\title{
Occupational Therapy-Related Assessments for Adults With Intellectual Disability: A Scoping Review
}

\author{
Wanda J. Mahoney, Meghan G. Blaskowitz, Khalilah R. Johnson
}

Importance: Occupational therapy practitioners use structured assessment tools to gather information from adults with intellectual disability (ID) in order to develop the occupational profile, guide occupational therapy intervention, and assess change over time.

Objective: To identify occupational therapy-related tools in the peer-reviewed literature for use in practice with adults with ID.

Data Sources: Peer-reviewed literature published between January 2002 and January 2018 included in CINAHL, PsycINFO, PubMed, and Scopus.

Study Selection and Data Collection: The review included articles that had information on occupational therapy-related assessment with adults $18 \mathrm{yr}$ or older who had primary or co-occurring ID.

Findings: Fifty-eight articles identified 73 occupational therapy-related assessment tools.

Conclusions and Relevance: This scoping review identified a broad range of assessment tools in the occupational therapy domain that are appropriate for adults with ID, some of which may be unfamiliar to occupational therapy practitioners.

What This Article Adds: This scoping review provides occupational therapy practitioners with a summary of occupational therapy-related assessment tools for adults with ID and an assessment reference guide.

n occupational therapy, structured assessment tools assist with collecting occupational profile information and are essential to analyze occupational performance and measure outcomes (American Occupational Therapy Association [AOTA], 2020); however, few assessment tools in occupational therapy are specifically intended for use with adults with intellectual disability (ID). ID is diagnosed in childhood and is a lifelong developmental disability involving significant cognitive impairment and issues with adaptive behavior or occupational performance (American Association on Intellectual and Developmental Disabilities [AAIDD], n.d.).

Although ID-specific assessment tools are uncommon, the assessment of adults with ID requires distinct considerations. When working with adults with ID, occupational therapy practitioners should be familiar with two major areas that have implications for assessment: adaptive behavior and self-determination.

Adaptive behavior consists of conceptual, social, and practical skills related to performance of many occupations (AAIDD, n.d.). Many tools are available to assess the adaptive behavior of people with ID because it is part of the diagnostic criteria for the condition. Adaptive-behavior measures are likely to be appropriate tools for occupational therapy practitioners because this behavior includes occupational performance and other areas of the occupational therapy domain, such as activities of daily living (ADLs), vocational skills, social skills, and problem solving.

Self-determination consists of skills, preferences, opportunities, and supports that enable people to make things happen in their lives. It is an essential aspect of quality of life (QOL) and a major occupational therapy outcome (AOTA, 2020; Simões \& Santos, 2016; Wehmeyer \& Abery, 2013). Adults with ID often experience lower levels of QOL and self-determination than people without disabilities (Blaskowitz et al., 2020; Simões \& Santos, 2016). The risk for 
decreased self-determination makes this an important assessment area for occupational therapy practitioners to consider when working with adults with ID (Angell et al., 2019; Dean et al., 2015).

Occupational therapy practitioners work with people with ID across the life course in various settings and need appropriate assessment strategies for this population. Because eligibility for special education services may continue until age 22, occupational therapy practitioners may work with adults with ID in school settings and require structured assessments to assist with transition services. In addition, occupational therapy services may be provided to adults with ID in settings in which they are the primary clients, such as state institutions for people with developmental disabilities, community group homes, vocational programs, or postsecondary programs (Berg et al., 2017; Johnson et al., 2019). Occupational therapy practitioners who work with programs for adults with ID may need assessment tools appropriate for overall program evaluation in addition to individual assessment. Adults with ID also receive occupational therapy services for coexisting health conditions in medical settings, such as hospitals and nursing homes, where identifying appropriate assessment tools for this population is a common challenge for occupational therapists (Mahoney et al., 2019).

Regardless of the setting, occupational therapy intervention with adults with ID may involve small changes in performance, and assessment tools need to be sufficiently sensitive to measure this change. For example, many occupational performance assessment tools rate a person's level of independence (i.e., minimal, moderate, or maximal assistance). Level of independence may not reflect the participation and QOL changes that can result for the adult with ID and their caregivers with occupational therapy intervention, because many adults with ID often continue to require some assistance.

Recent scoping reviews have concentrated on intervention with people with ID (e.g., Blaskowitz et al., 2021; Waldman-Levi et al., 2019). In contrast to these previous reviews, the aim of this study was to identify assessment tools within the domain of occupational therapy practice used in the literature with adults with ID.

\section{Method}

We followed the five-step scoping review procedure as outlined by Arksey and O'Malley (2005). A scoping review is an appropriate framework to synthesize existing knowledge that addresses an exploratory research question aimed at mapping key concepts and the range of available evidence (Arksey \& O'Malley, 2005). This study's focus on assessment tools arose from the initial findings of a broader scoping review performed to examine the literature on occupational therapy practice with adults with ID.

\section{Step 1: Develop a Research Question}

After reviewing the preliminary results of an exploratory search in consultation with a university librarian with expertise in conducting scoping reviews, we determined the broad research question "What is the scope of the evidence related to occupational therapy practice with adults with ID?" As a result of the unanticipated volume of literature captured, we created subquestions on assessment, intervention, and descriptive background evidence (also see Blaskowitz et al., 2021). This article focuses on the subquestion "What is the scope of the evidence on occupational therapy-related assessment with adults with ID?"

\section{Step 2: Identify Relevant Literature}

Together with the consulting librarian, we finalized key words to perform custom searches in CINAHL, PsycINFO, PubMed, and Scopus. Controlled vocabulary terms included intellectual disability, mental retardation, learning disability (used in the United Kingdom), cognitive impairment, adult, and occupational therapy (Blaskowitz et al., 2021). All citations and abstracts from the searches were first exported to EndNote and then to Covidence (Veritas Health Innovation, 2019), an online review management system used to categorize and track articles. 


\section{Step 3: Select Studies}

Articles for the larger scoping review met the following inclusion criteria: (1) published in English between January 2002 and January 2018, (2) published in a peer-reviewed journal, (3) included content about people ages $18 \mathrm{yr}$ or older with primary or coexisting ID at any level, and (4) included information relevant to occupational therapy practice. The exclusion criteria were (1) literary criticism or conference proceedings; (2) gray literature (e.g., dissertations); or (3) focused on participants with physical, developmental, or cognitive disabilities without ID (e.g., adult-onset muscular dystrophy, Asperger syndrome, mild cognitive impairment; Blaskowitz et al., 2021).

Two different authors reviewed each article for inclusion, and we all discussed and came to consensus in the event of any disagreements. For example, discussion was required to determine whether Kjellberg et al. (2003) included adults with primary or coexisting ID because the article described an assessment tool completed with adults with learning disability. Although the study took place in Sweden, two of the authors were from the United Kingdom, where learning disability is the term used for ID. It was not clear from the article whether the participants' learning disability was actually ID, so we excluded this article from the review.

\section{Step 4: Map the Data}

To establish reliability, we screened 60 titles and abstracts, reaching $90 \%$ consistency. We identified 3,402 articles for screening, and 159 met the inclusion criteria (Figure 1). Two different authors conducted full-text screening of each article, and we all discussed and came to a consensus regarding any disagreements about inclusion. We extracted key information (e.g., purpose of the study, assessment tools and data collection measures, participants, occupations addressed, implications for occupational therapy evaluation) into an Excel spreadsheet (Version 2016; Microsoft, Redmond, WA). For each article, one author completed the initial data extraction, and a second author reviewed and added to this information.

Because this review focused on assessment, we reviewed all articles that used assessment or data collection strategies with adults with ID within the domain of occupational therapy, as defined by the Occupational Therapy Practice Framework: Domain and Process - Fourth Edition (AOTA, 2020). For example, IQ tests are often used with adults with ID, but they are not included in this review because, with the exception of adaptive behavior assessments, they are not in the occupational therapy domain. We reviewed each assessment strategy to determine its clinical relevance on the basis of our experience as occupational therapists who work with people with ID and came to a consensus about the inclusion of each tool. In addition to published assessment tools, we included research tools or strategies if they were sufficiently described in the article to allow for their application in clinical practice.

\section{Step 5: Evaluate and Summarize Findings}

We reviewed the extracted data and original articles to code assessment strategies in the articles according to the occupational therapy domain topic of each assessment. We used an iterative, inductive process and consensus discussions to develop the codes and determine the frequency of each code. We included codes for psychometrics and strategies to assess programs or groups in addition to domain topic codes. We sought additional information about assessment tools from online sources, articles, and manuals; this information is included in an assessment reference guide (Table A.1 in the Appendix).

\section{Results}

The search yielded 58 articles with information on 73 distinct assessment tools for adults with ID within the domain of occupational therapy. Assessment tools appeared in the included articles primarily as research data collection tools or in examples illustrating their use with adults with ID. The assessment tools focused on occupational performance and participation, person factors, environmental factors, or all of these. Occupational performance and participation assessments evaluated ADLs, work, leisure, or multiple areas of occupation. Person factor assessments measured cognition and perception (i.e., mental functions), social skills, sensory processing, pain, and physical abilities. 
Figure 1. Flow diagram for inclusion and exclusion of studies in the scoping review.

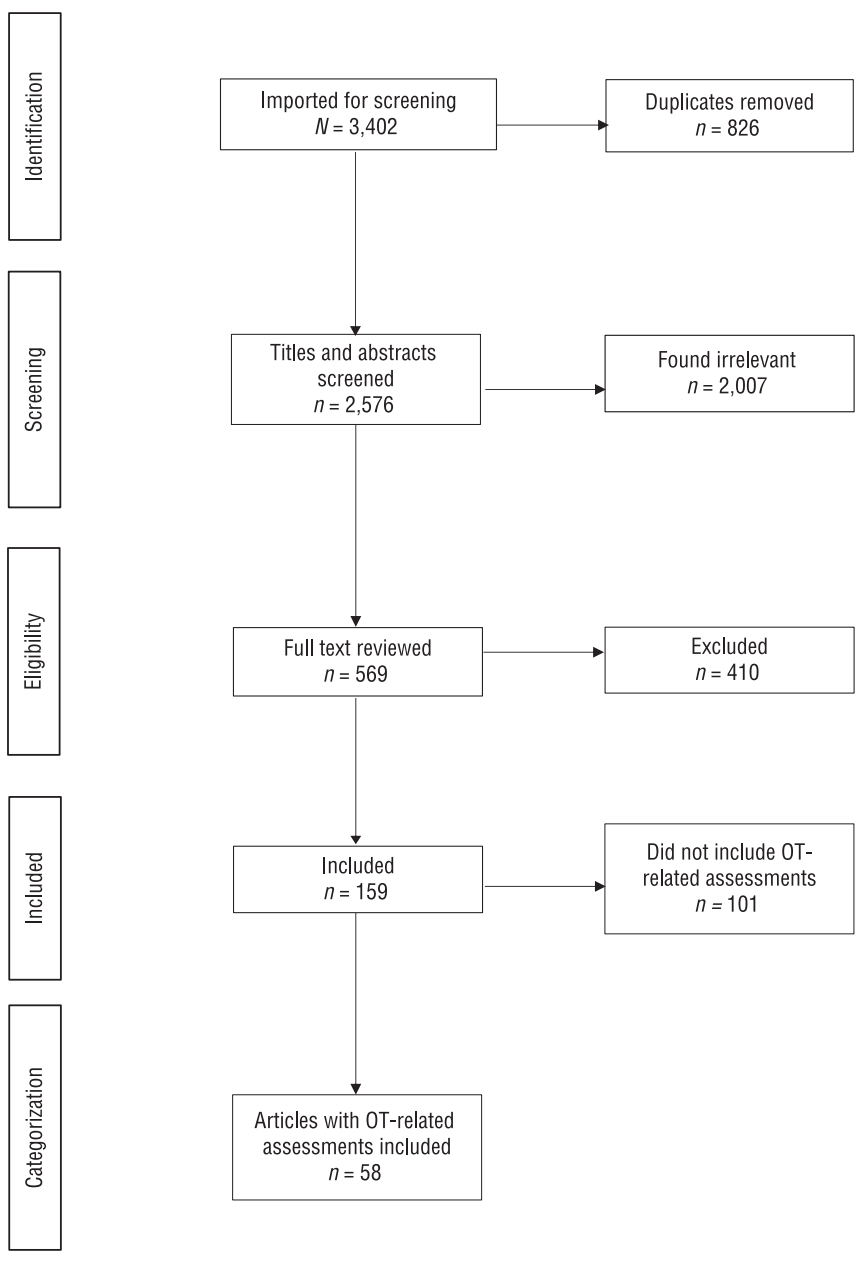

Note. OT = occupational therapy. Figure format from "Preferred Reporting Items for Systematic Reviews and Meta-Analyses: The PRISMA Statement," by D. Moher, A. Liberati, J. Tetzlaff, and D. G. Altman; PRISMA Group, 2009, PLoS Medicine, 6(7), e1000097. https://doi.org/10.1371/journal.pmed.100009
Environmental assessments focused on social support for adults with ID. In addition to individual assessment, some researchers used tools with group programs as an initial needs assessment or to evaluate program outcomes. Table A.1 includes a complete list of the assessments. Articles that focused on psychometrics of assessment tools are included in Table A.2.

\section{Participation and Quality of Life}

Seventeen assessment tools focused on participation of adults with ID across multiple occupations, including ADLs, community participation, and employment. These tools also assessed broad areas of self-determination and QOL (see Table A.1). Participation and QOL assessments, such as the Volitional Questionnaire (VQ) or Canadian Occupational Performance Measure, can inform occupational profiles and intervention planning or measure outcomes (de las Heras et al., 2007; Law et al., 2005; Mahoney et al., 2016; Mirza \& Hammel, 2009). Although some of these assessments use self-report ratings by adults with ID or observation to understand their participation and QOL, the majority rely on caregiver report.

Some participation and QOL assessment tools were developed by professionals outside occupational therapy, but occupational therapy practitioners can use them to understand the strengths and needs of adults with ID. For example, the Supports Intensity Scale (Thompson et al., 2004) helps practitioners identify the current supports adults with ID have and their unmet support needs, information that is valuable to maximize participation in occupations (e.g., Dean et al., 2015). Similarly, adaptive behavior assessments, although designed to be diagnostic tools for ID, can also be used

by occupational therapy practitioners to support intervention planning in ADLs, social participation, leisure, work, or other assessed areas (Table A.1; e.g., Berg et al., 2017).

QOL and self-determination assessments encompass many occupations and often involve a combination of self-report and family- or staff-report versions. Self-determination, an aspect of QOL, is an important consideration for adults with ID (Dean et al., 2015), and the Arc's Self-Determination Scale was the tool most commonly identified in this scoping review to assess the level of control and choice-making that adults with ID have in their lives (Wehmeyer, 1995; e.g., Stock et al., 2011).

\section{Activities of Daily Living}

The most frequent assessment domain referenced in this scoping review was performance of ADLs and instrumental activities of daily living (IADLs). We found 24 distinct assessment tools for the domain of ADLs (Table 1). The most frequently cited tool was the Assessment of Motor and Process Skills (AMPS; Fisher \& Bray Jones, 2012), an 
Table 1. Articles That Included Occupational Therapy-Related Assessments for Adults With ID

\begin{tabular}{|c|c|c|}
\hline Assessment Focus & No. of Articles ${ }^{a}$ & No. of Assessment Tools ${ }^{b}$ \\
\hline \multicolumn{3}{|l|}{ Occupational performance and participation } \\
\hline Participation and quality of life & 18 & 17 \\
\hline Activities of daily living & 27 & 24 \\
\hline Vocational skills and work performance & 4 & 7 \\
\hline Leisure & 1 & 1 \\
\hline \multicolumn{3}{|l|}{ Person factors } \\
\hline Social skills & 8 & 7 \\
\hline Cognition or perception & 8 & 7 \\
\hline Sensory & 3 & 2 \\
\hline Other person factors & 3 & 3 \\
\hline \multicolumn{3}{|l|}{ Environment factors } \\
\hline Social support & 6 & 8 \\
\hline \multicolumn{3}{|l|}{$\begin{array}{l}\text { Group or population needs assessment and } \\
\text { program evaluation }\end{array}$} \\
\hline Program assessment & 5 & Included in other categories \\
\hline
\end{tabular}

Note. See Appendix for complete reference list of assessment tools and included articles. ID = intellectual disability.

aTotal number of articles exceeds 58 total articles in review because some articles included

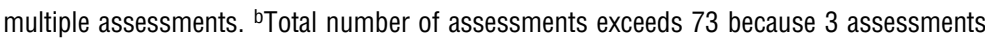
were coded in two categories. observation tool designed by occupational therapists to assess the quality of $A D L$ and IADL performance in addition to motor and process skills (e.g., Fisher et al., 2017).

Adaptive behavior assessments also provide insight into ADL performance of adults with ID, in addition to other domains (e.g., Berg et al., 2017). Although many ADL assessments cover multiple daily living occupations, some assessments target a specific ADL, such as power mobility use for people with severe or profound ID or safety issues with eating (e.g., Benford, 2017; Sheppard et al., 2017; see Table A.1).

Modifications to interviews about ADLs or other areas may be necessary to include adults with ID in the assessment process. Jurkowski and Paul-Ward (2007) used a photovoice process to enable adults with ID to share their

views about health promotion. This adapted interview process, which can be used in clinical practice, involves providing a camera to adults with ID. Their photographs can be used to help them answer questions and as visual supports to aid the interview.

Another ADL assessment strategy used in the literature with adults with ID is Goal Attainment Scaling, a means of tracking progress during intervention and measuring outcomes (Kiresuk et al., 2014). Goal Attainment Scaling can be used to assess any occupation or other factor; in the literature on adults with ID, it was used to assess ADL performance (Benford, 2017; Urwin \& Ballinger, 2005).

\section{Work or Leisure}

Seven assessments identified in this scoping review focused on vocational skills or work performance of adults with ID, and one tool was developed to measure leisure with young adults with ID (Table 1; Table A.1). Career planning tools that focus on individual preferences and skills may be common in secondary educational settings and are within the domain of occupational therapy. A review of career planning tools found five self-report or observation-based vocational tools appropriate for adults with ID (Murray et al., 2016). In a work setting, self-report tools can identify perceived supports and barriers at work. Observational tools, such as the Work Personality Profile, are also appropriate for identifying competence in specific vocational skills (Bolton \& Neath, 2008; e.g., Liu et al., 2013).

\section{Person Factors}

Nineteen assessments identified in this scoping review concentrated on person factors of adults with ID (see Table A.1). Major areas for person factor assessments included cognition and perception, social skills, sensory processing, and other factors, such as physical abilities.

\section{Cognitive Assessments}

Seven cognitive assessments found in the literature can be used to understand the mental functions of an adult with ID. Jang, Chern, and Lin (2009) suggested that occupational therapy practitioners assess cognition of adults with ID in 
vocational and educational settings because it is a major influence on work and educational performance. Cognitive decline is a potential concern for older adults with ID, and the Dementia Screening Questionnaire for Individuals With Intellectual Disabilities can identify such decline (Deb et al., 2007; Naick, 2017).

\section{Social Skills Assessments}

Seven assessments detailed in the literature provide information on a person's ability to interact socially, build social networks, and regulate emotions or behavior (see Table A.1). Challenging behavior was frequently part of social skills assessments for adults with ID, for whom self-injurious or aggressive behavior can significantly interfere with participation (e.g., Koritsas et al., 2008). The most common occupational therapy tools to assess social skills were observational tools of social interaction skills (e.g., Fisher et al., 2017).

\section{Sensory and Other Person Factor Assessments}

Two sensory assessments and three additional assessments addressed pain or motor abilities for adults with ID in the literature (see Table A.1). Occupational therapy-designed sensory tools included a self-report questionnaire that may need to be adapted or used as an interview with adults with ID and a caregiver or professional report intended for people with developmental disabilities (e.g., Urwin \& Ballinger, 2005; see Table A.1). A pain assessment was developed for caregivers or health care providers to rate indicators of pain for adults with ID who have limited communication abilities (Lotan et al., 2009).

\section{Social Support}

Social support was the only environmental factor assessed in the articles in this review. Eight assessment tools describe social support provided by family members or others to adults with ID. The Supports Intensity Scale (Thompson et al., 2004), classified in this review as both a Participation and QOL tool and a Social Support tool, provides information about social support networks of people with ID and how this support affects their selfdetermination and occupational performance (e.g., Koritsas et al., 2008). Some social support assessment tools focus on caregiver stress, which affects the participation of adults with ID (e.g., Magill-Evans et al., 2011).

\section{Program Assessment}

A subset of authors used assessment tools to determine the need for a new program or to evaluate existing programs that support adults with ID. For example, Boland et al. (2008) included the interview tool they created on the basis of several published assessments to learn the perspectives of adults with ID and their caregivers. These interviews served as a needs assessment for health promotion programming. Liu et al. (2013) used two social skills assessments and a vocational assessment to evaluate the effectiveness of a work training program for adults with autism and ID that was designed by occupational therapists and implemented by rehabilitation assistants.

\section{Psychometrics}

Thirteen articles included in this review were research studies of the psychometric properties of 14 assessment tools for adults with ID (see Table A.2). These assessment tools were existing tools being tested to determine their appropriateness for adults with ID, adaptations or translations of existing tools, and new assessment tools. Authors found that existing tools, such as the AMPS, yielded valid scores with adults with ID (Fisher \& Bray Jones, 2012; Kottorp et al., 2003b). In contrast, researchers found significant concerns with the interrater reliability of scores from the Revised Irrabeena Core Skills Assessment, an Australian tool designed for staff members to rate the daily living skills of adults with ID (McGregor, 2007; Milasinovic \& Buchanan, 2013). New assessment tools included several designed for people 
with severe to profound ID, such as the Choking Risk Assessment and the Assessment of Learning Powered Mobility (Nilsson \& Durkin, 2014; Nilsson et al., 2011; Sheppard et al., 2017).

\section{Discussion}

Occupational therapy practitioners may have varying levels of familiarity with the 73 assessment tools identified in this review, especially those created by other professionals. The assessment reference guide (Table A.1) can serve as a useful resource for occupational therapy practitioners working with adults with ID. This evidence-informed resource can assist occupational therapists in selecting appropriate assessments to use with adults with ID for initial assessment, progress monitoring, outcomes measurement, or program evaluation. Assessment processes that take a $360^{\circ}$ view of the adult with ID, from the perspective of the individual, caregivers, and practitioners or support staff who know them well, may provide a more accurate picture of the person's strengths, needs, and priorities, especially for those with limited communication.

Learning the perspective of clients is necessary for person-centered practice, and engaging adults with ID in inclusive assessment and planning processes can improve their self-determination, also an important factor for occupational therapy practice (Angell et al., 2019; AOTA, 2020; Wehmeyer \& Abery, 2013). Occupational therapy practitioners may need to adapt structured self-report assessment tools or use other methods to enable adults with ID to share their perspectives and engage the person's voice in the assessment and intervention planning process. Assessment modifications to elicit information from adults with ID include simplifying questions and using photographs (Boland et al., 2008; Jurkowski \& Paul-Ward, 2007). Observation is another way to ascertain the perspectives of adults with ID, using a tool such as the VQ (de las Heras et al., 2007).

Structured observation is a valuable assessment method, especially for adults with severe or profound ID. For example, researchers used the VQ to rate observed levels of involvement in day program activities (Mahoney et al., 2016). Nilsson, Eklund, Nyberg, and Thulesius (2011) provided a structured observation chart that occupational therapy practitioners can adapt to assess adults with profound ID and their level of involvement in multiple occupations beyond the power wheelchair mobility for which it was designed.

Occupational therapists should also consider selecting outcome measures for adults with ID that are sensitive to small changes that may result from occupational therapy intervention. Researchers demonstrated how Goal Attainment Scaling for individualized goals, created with the client and potentially with caregivers, can be used to measure outcomes with the population (Benford, 2017; Urwin \& Ballinger, 2005). The focus of outcome measures may need to be on participation and support needs rather than on person factors. Many adaptive behavior assessments emphasize participation in a variety of occupations and are appropriate for initial occupational therapy assessment; however, these diagnostic tools may not be sufficiently sensitive to change to be used as outcome measures for occupational therapy intervention (Bryze, 2020).

The AMPS, the most frequently cited assessment in this review, is an occupational therapy-designed tool appropriate for use with adults with ID that provides a structured way to observe and rate ADL performance (Fisher \& Bray Jones, 2012). The formal certification process required before using the AMPS as a standardized assessment may be a barrier for some occupational therapy practitioners. Fisher and Marterella (2019), however, provided information about how to use the AMPS as a nonstandardized observation assessment.

Occupational therapy practitioners may also find themselves supporting adults with ID outside of direct service provision as consultants or program evaluators (Johnson et al., 2019). Some articles explicitly discussed assessment of groups of adults with ID, which can inform program evaluation. As more state health systems for adults with ID move toward value-based payment structures under the Patient Protection and Affordable Care Act (2010; Pub. L. 111-148), it is increasingly important that occupational therapy practitioners use assessment tools to measure program- and population-level outcomes (Blaskowitz et al., 2020). These articles also serve as examples of how research methods can inform clinical program evaluation (e.g., Mirza \& Hammel, 2009). 
This scoping review expands on existing occupational therapy research on assessment tools by focusing on adults with ID (e.g., Romli et al., 2019). Moreover, by including any tool within the occupational therapy domain, this study builds on a previous systematic review and literature reviews on assessment tools appropriate for people with ID that focused on specific occupations, such as career planning or community mobility (Murray et al., 2016; Stock et al., 2011). Although psychometrics research is important for evidence-based practice, this review demonstrates that research on the measurement properties of assessment tools is not the only research evidence that can inform assessment selection. Future research may explore the assessments used in occupational therapy practice with adults with ID, including how occupational therapy practitioners assess areas for which this review found no evidence, such as the physical environment.

\section{Limitations}

The primary limitation of this scoping review is that it may not have captured all articles with relevant assessment tools, especially because we did not conduct a hand search when the scope of literature found was more extensive than anticipated. For example, activity card sort assessments are appropriate for use with adults with ID, but none of the articles we located demonstrated their use with this population (Bryze, 2020). We also did not locate additional selfdetermination assessment tools for adults with ID (e.g., Abery et al., 2000; Wolman et al., 1994). The chief limitation of the scoping review methodology is that it does not include an assessment of the quality of evidence.

\section{Implications for Occupational Therapy Practice}

This scoping review has the following implications for occupational therapy practice:

- Many assessment tools are appropriate for occupational therapy practitioners working with adults with ID, especially those created by other professionals that include areas important to occupational therapy, such as selfdetermination and social support. The assessment resource guide in Table A.1 provides information on tools for use with adults with ID that are within the scope of occupational therapy.

- Person-centered occupational therapy evaluation and intervention planning with adults with ID must engage adults with ID, and this review provides examples of self-report tools, observation tools, and interview modifications to gather their perspectives and support self-determination.

- Occupational therapy practitioners can use resources identified in this scoping review to inform assessment selection and monitor and evaluate outcomes for programs for adults with ID in addition to individual evaluation.

\section{Conclusion}

This scoping review identified a broad range of assessment tools within the occupational therapy domain that are appropriate for use with adults with ID. Occupational therapy practitioners may need to look beyond assessments created in occupational therapy to incorporate areas essential for people with ID, such as self-determination and social support. In addition, occupational therapy practitioners need to modify assessment processes or select tools to ensure that the perspectives of adults with ID are reflected in the occupational therapy process.

\section{References}

Abery, B.H., Elkin, S.V., Smith, J.G., Springborg, H.L., \& Stancliffe, R.J. (2000). Minnesota Self-Determination Scales. University of Minnesota, Institute on Community Integration.

American Association on Intellectual and Developmental Disabilities. (n.d.). Definition of intellectual disability. http://aaidd.org/intellectual-disability/ definition\#.WdOb5GhSyUk

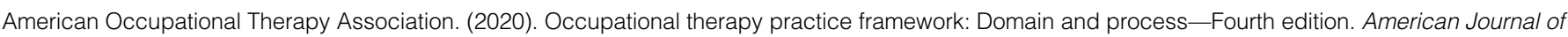
Occupational Therapy, 74(Suppl. 2), 7412410010. https://doi.org/10.5014/ajot.2020.74S2001

*Andrews, J., Leonard, H., Hammond, G. C., Girdler, S., Rajapaksa, R., Bathgate, K., \& Downs, J. (2014). Community participation for girls and women living with Rett syndrome. Disability and Rehabilitation, 36, 894-899. https://doi.org/10.3109/09638288.2013.813083 
Angell, A. M., Carroll, T. C., Bagatell, N., Chen, C., Kramer, J. M., Schwartz, A., . . Hammel, J. (2019). Understanding self-determination as a crucial component in promoting the distinct value of occupational therapy in post-secondary transition planning. Journal of Occupational Therapy, Schools and Early Intervention, 12, 129-143. https://doi.org/10.1080/19411243.2018.1496870

Arksey, H., \& O'Malley, L. (2005). Scoping studies: Towards a methodological framework. International Journal of Social Research Methodology, 8, $19-32$. https://doi.org/10.1080/1364557032000119616

*Barker, E. T., Hartley, S. L., Seltzer, M. M., Floyd, F. J., Greenberg, J. S., \& Orsmond, G. I. (2011). Trajectories of emotional well-being in mothers of adolescents and adults with autism. Developmental Psychology, 47, 551-561. https://doi.org/10.1037/a0021268

*Benen Demchick, B., Eskow, K. G., \& Crabtree, L. A. (2014). Autism and transitioning youth: A pilot study of sensory processing and family quality of life. Journal of Occupational Therapy, Schools and Early Intervention, 7, 54-69. https://doi.org/10.1080/19411243.2014.898492

*Benford, F. (2017). Use of powered mobility for a young adult with profound and multiple learning disabilities: A practice analysis. British Journal of Occupational Therapy, 80, 517-520. https://doi.org/10.1177/0308022617698169

*Berg, L. A., Jirikowic, T., Haerling, K., \& MacDonald, G. (2017). Navigating the hidden curriculum of higher education for postsecondary students with intellectual disabilities. American Journal of Occupational Therapy, 71, 7103100020. https://doi.org/10.5014/ajot.2017.024703

Blaskowitz, M. G., Johnson, K. R., \& Mahoney, W. J. (2021). Evidence to inform occupational therapy intervention with adults with intellectual disability: A scoping review. American Journal of Occupational Therapy, 75, 7503180010. https://doi.org/10.5014/ajot.2021.043562

Blaskowitz, M. G., Scott, P. W., Randall, L., Zelenko, M., Green, B. M., McGrady, E., . . Lonergan, M. (2020). Closing the gap: Identifying self-reported quality of life differences between youth with and without intellectual and developmental disabilities. Inclusion, 8, 241-254. https://doi.org/10.1352/2326-6988-8.3.241

*Boland, M., Daly, L., \& Staines, A. (2008). Methodological issues in inclusive intellectual disability research: A health promotion needs assessment of people attending Irish disability services. Journal of Applied Intellectual Disabilities, 21, 199-209. https://doi.org/10.1111/j.1468-3148.2007.00404.x

Bolton, B., \& Neath, J. (2008). Work Personality Profile and Computer Report (WPP). PRO-ED.

*Borioni, N., Marinaro, P., Celestini, S., Del Sole, F., Magro, R., Zoppi, D., . . Bonassi, S. (2012). Effect of equestrian therapy and onotherapy in physical and psycho-social performances of adults with intellectual disability: A preliminary study of evaluation tools based on the ICF classification. Disability and Rehabilitation, 34, 279-287. https://doi.org/10.3109/09638288.2011.605919

Bryze, K. (2020). Evaluation of occupational performance and engagement. In K. Bryze (Ed.), Occupational therapy for adults with intellectual disability (pp. 73-86). Slack.

${ }^{*}$ Cardell, B., Swain, L. J., \& Burnett, A. (2013). Construct validity of the functionally simulated technology task: An exploratory study. Occupational Therapy in Health Care, 27, 345-354. https://doi.org/10.3109/07380577.2013.845928

${ }^{*}$ Collado, V., Faulks, D., \& Hennequin, M. (2008). A survey of the difficulties encountered during routine hygiene and health care by persons with special needs. Disability and Rehabilitation, 30, 1047-1054. https://doi.org/10.1080/09638280701616574

*Davies, B., Griffiths, J., Liddiard, K., Lowe, K., \& Stead, L. (2015). Changes in staff confidence and attributions for challenging behaviour after training in positive behavioural support within a forensic medium secure service. Journal of Forensic Psychiatry and Psychology, 26, 847-861. https://doi.org/10. 1080/14789949.2015.1072574

*Dean, E. E., Dunn, W., \& Tomchek, S. (2015). Role of occupational therapy in promoting self-determination through consumer-directed supports. Occupational Therapy in Health Care, 29, 86-95. https://doi.org/10.3109/07380577.2014.958887

Deb, S., Hare, M., Prior, L., \& Bhaumik, S. (2007). Dementia Screening Questionnaire for Individuals With Intellectual Disabilities. British Journal of Psychiatry, 190, 440-444. https://doi.org/10.1192/bjp.bp.106.024984

de las Heras, C. G., Geist, R., Kielhofner, G., \& Li, Y. (2007). A user's guide to the Volitional Questionnaire (Version 4.1). University of Illinois at Chicago.

*Dwyer, J., \& Reep, J. (2008). How occupational therapists assess adults with learning disabilities. Advances in Mental Health and Learning Disabilities, 2 , 9-14. https://doi.org/10.1108/17530180200800034

*Dychawy-Rosner, I., \& Eklund, M. (2003). Content validity and clinical applicability of the Irena Daily Activity assessment measuring occupational performance in adults with developmental disability. Occupational Therapy International, 10, 127-149. https://doi.org/10.1002/oti.181

Fisher, A. G., \& Bray Jones, K. (2012). Assessment of Motor and Process Skills: Vol. 1. Development, standardization, and administration manual (7th ed.). Three Star Press.

${ }^{*}$ Fisher, A. G., Griswold, L. A., Munkholm, M., \& Kottorp, A. (2017). Evaluating domains of everyday functioning in people with developmental disabilities. Scandinavian Journal of Occupational Therapy, 24, 1-9. https://doi.org/10.3109/11038128.2016.1160147

Fisher, A. G., \& Marterella, A. (2019). Powerful practice: A model for authentic occupational therapy. Center for Innovative OT Solutions.

*Gat, O., \& Yalon-Chamovitz, S. (2010). Perceived quality of life among adults with severe intellectual and physical disability, family members and caretakers. Israeli Journal of Occupational Therapy, 1, e9-e24.

*Green, D., Beaton, L., Moore, D., Warren, L., Wick, V., Sanford, J. E., \& Santosh, P. (2003). Clinical incidence of sensory integration difficulties in adults with learning disabilities and illustration of management. British Journal of Occupational Therapy, 66, 454-463. https://doi.org/10.1177/030802260306601004

*Hällgren, M., \& Kottorp, A. (2005). Effects of occupational therapy intervention on activities of daily living and awareness of disability in persons with intellectual disabilities. Australian Occupational Therapy Journal, 52, 350-359. https://doi.org/10.1111/j.1440-1630.2005.00523.x

*Hällgren, M., Nygård, L., \& Kottorp, A. (2011). Technology and everyday functioning in people with intellectual disabilities: A Rasch analysis of the Everyday Technology Use Questionnaire (ETUQ). Journal of Intellectual Disability Research, 55, 610-620. https://doi.org/10.1111/j.1365-2788.2011.01419.x 
*Hällgren, M., Nygård, L., \& Kottorp, A. (2014). Everyday technology use among people with mental retardation: Relevance, perceived difficulty, and influencing factors. Scandinavian Journal of Occupational Therapy, 21, 210-218. https://doi.org/10.3109/11038128.2013.862295

*Hammel, J., Lai, J. S., \& Heller, T. (2002). The impact of assistive technology and environmental interventions on function and living situation status with people who are ageing with developmental disabilities. Disability and Rehabilitation, 24, 93-105. https://doi.org/10.1080/09638280110063850

*Harr, N., Dunn, L., \& Price, P. (2011). Case study on effect of household task participation on home, community, and work opportunities for a youth with multiple disabilities. Work, 39, 445-453. https://doi.org/10.3233/WOR-2011-1194

*Jang, Y., Chang, T. C., \& Lin, K. C. (2009). Reliability and validity of a physical capacity evaluation used to assess individuals with intellectual disabilities and mental illness. International Journal of Rehabilitation Research, 32, 77-84. https://doi.org/10.1097/MRR.0b013e32830f912f

*Jang, Y., Chern, J. S., \& Lin, K. C. (2009). Validity of the Loewenstein Occupational Therapy Cognitive Assessment in people with intellectual disabilities. American Journal of Occupational Therapy, 63, 414-422. https://doi.org/10.5014/ajot.63.4.414

*Jeong, B., Yoo, E., Jung, M., Kang, D., Park, S., \& Park, S. H. (2013). Validity and reliability of the Korean version of the Behaviour Problems Inventory. Journal of Applied Research in Intellectual Disabilities, 26, 578-590. https://doi.org/10.1111/jar.12054

Johnson, K. R., Blaskowitz, M., \& Mahoney, W. (2019). Occupational therapy practice with adults with intellectual disability: What more can we do? Open Journal of Occupational Therapy, 7(2). https://doi.org/10.15453/2168-6408.1573

*Jurkowski, J. M., \& Paul-Ward, A. (2007). Photovoice with vulnerable populations: Addressing disparities in health promotion among people with intellectual disabilities. Health Promotion Practice, 8, 358-365. https://doi.org/10.1177/1524839906292181

*Kåhlin, I., \& Haglund, L. (2009). Psychosocial strengths and challenges related to work among persons with intellectual disabilities. Occupational Therapy in Mental Health, 25, 151-163. https://doi.org/10.1080/01642120902859055

*King, E., Okodogbe, T., Burke, E., McCarron, M., McCallion, P., \& O'Donovan, M. A. (2017). Activities of daily living and transition to community living for adults with intellectual disabilities. Scandinavian Journal of Occupational Therapy, 24, 357-365. https://doi.org/10.1080/11038128.2016.1227369

Kiresuk, T. J., Smith, A., \& Cardillo, J. E. (2014). Goal attainment scaling: Applications, theory, and measurement. Taylor \& Francis. https://doi.org/10.4324/ 9781315801933

*Kjellberg, A. (2002). More or less independent. Disability and Rehabilitation, 24, 828-840. https://doi.org/10.1080/09638280210131745

Kjellberg, A., Haglund, L., Forsyth, K., \& Kielhofner, G. (2003). The measurement properties of the Swedish version of the Assessment of Communication and Interaction Skills. Scandinavian Journal of Caring Sciences, 17, 271-277. https://doi.org/10.1046/j.1471-6712.2003.00225.x

*Koritsas, S., lacono, T., Hamilton, D., \& Leighton, D. (2008). The effect of active support training on engagement, opportunities for choice, challenging behaviour and support needs. Journal of Intellectual and Developmental Disability, 33, 247-256. https://doi.org/10.1080/13668250802282944

*Kottorp, A. (2008). The use of the Assessment of Motor and Process Skills (AMPS) in predicting need of assistance for adults with mental retardation. OTJR: Occupation, Participation and Health, 28, 72-80. https://doi.org/10.3928/15394492-20080301-04

*Kottorp, A., Bernspång, B., \& Fisher, A. G. (2003a). Activities of daily living in persons with intellectual disability: Strengths and limitations in specific motor and process skills. Australian Occupational Therapy Journal, 50, 195-204. https://doi.org/10.1111/j.1440-1630.2003.00401.x

*Kottorp, A., Bernspång, B., \& Fisher, A. G. (2003b). Validity of a performance assessment of activities of daily living for people with developmental disabilities. Journal of Intellectual Disability Research, 47, 597-605. https://doi.org/10.1046/j.1365-2788.2003.00475.x

*Kottorp, A., Hällgren, M., Bernspång, B., \& Fisher, A. G. (2003). Client-centered occupational therapy for persons with mental retardation: Implementation of an intervention programme in activities of daily living tasks. Scandinavian Journal of Occupational Therapy, 10, 51-60. https://doi.org/10.1080/ 11038120310009416

*Kramer, J. M., \& Schwartz, A. (2017). Refining the Pediatric Evaluation of Disability Inventory-Patient-Reported Outcome (PEDI-PRO) item candidates: Interpretation of a self-reported outcome measure of functional performance by young people with neurodevelopmental disabilities. Developmental Medicine and Child Neurology, 59, 1083-1088. https://doi.org/10.1111/dmcn.13482

Law, M., Baptiste, S., Carswell, A., McColl, M. A., Polatajko, H. J., \& Pollock, N. (2005). Canadian Occupational Performance Measure (4th ed.). CAOT Publications ACE.

*Lin, L. Y., Yu, S. N., \& Yu, Y. T. (2012). A study of activities of daily living and employment in adults with autism spectrum disorders in Taiwan. International Journal of Rehabilitation Research, 35, 109-115. https://doi.org/10.1097/MRR.0b013e32835108b1

*Liu, K. P. Y., Wong, D., Chung, A. C. Y., Kwok, N., Lam, M. K. Y., Yuen, C. M. C., . . Kwan, A. C. S. (2013). Effectiveness of a workplace training programme in improving social, communication and emotional skills for adults with autism and intellectual disability in Hong Kong-A pilot study. Occupational Therapy International, 20, 198-204. https://doi.org/10.1002/oti.1356

*Lotan, M., Moe-Nilssen, R., Ljunggren, A. E., \& Strand, L. I. (2009). Reliability of the Non-Communicating Adult Pain Checklist (NCAPC), assessed by different groups of health workers. Research in Developmental Disabilities, 30, 735-745. https://doi.org/10.1016/j.ridd.2008.10.005

*Magill-Evans, J., Darrah, J., \& Galambos, N. L. (2011). The parenting journey of mothers of young adults with multiple impairments. Journal of Developmental and Physical Disabilities, 23, 183-193. https://doi.org/10.1007/s10882-010-9214-0

Mahoney, W. J., Ceballos, J., \& Amir, N. (2019). Occupational therapy practitioners' perceptions about older adults with developmental disabilities in traditional health care settings. American Journal of Occupational Therapy, 73, 7303345010. https://doi.org/10.5014/ajot.2019.029835

*Mahoney, W., \& Roberts, E. (2009). Co-occupation in a day program for adults with developmental disabilities. Journal of Occupational Science, 16, 170-179. https://doi.org/10.1080/14427591.2009.9686659

*Mahoney, W. J., Roberts, E., Bryze, K., \& Parker Kent, J. A. (2016). Occupational engagement and adults with intellectual disabilities. American Journal of Occupational Therapy, 70, 7001350030. https://doi.org/10.5014/ajot.2016.016576 
McGregor, J. (2007). Revised Irrabeena Core Skills Assessment (RICSA): Assessment record. Disability Services Commission.

*Milasinovic, V., \& Buchanan, A. (2013). Reliability of an assessment used in formal accommodation services: Implications for adults with an intellectual disability. Journal of Intellectual and Developmental Disability, 38, 301-309. https://doi.org/10.3109/13668250.2013.805737

*Mirza, M., \& Hammel, J. (2009). Consumer-directed goal planning in the delivery of assistive technology services for people who are ageing with intellectual disabilities. Journal of Applied Research in Intellectual Disabilities, 22, 445-457. https://doi.org/10.1111/j.1468-3148.2009.00495.x

Moher, D., Liberati, A., Tetzlaff, J., \& Altman, D. G.; PRISMA Group. (2009). Preferred Reporting Items for Systematic Reviews and Meta-Analyses: The PRISMA statement. PLoS Medicine, 6(7), e1000097. https://doi.org/10.1371/journal.pmed.100009

*Murray, N., Hatfield, M., Falkmer, M., \& Falkmer, T. (2016). Evaluation of career planning tools for use with individuals with autism spectrum disorder: A systematic review. Research in Autism Spectrum Disorders, 23, 188-202. https://doi.org/10.1016/j.rasd.2015.12.007

*Naick, M. (2017). Innovative approaches to using assistive technology to support carers to care for people with night time incontinence issues. World Federation of Occupational Therapists Bulletin, 73, 128-130. https://doi.org/10.1080/14473828.2017.1302156

Nilsson, L., \& Durkin, J. (2014). Assessment of learning powered mobility use_Applying grounded theory to occupational performance. Journal of Rehabilitation Research and Development, 51, 963-974. https://doi.org/10.1682/JRRD.2013.11.0237

*Nilsson, L., Eklund, M., \& Nyberg, P. (2011). Driving to Learn in a powered wheelchair: Inter-rater reliability of a tool for assessment of joystick-use. Australian Journal of Occupational Therapy, 58, 447-454. https://doi.org/10.1111/j.1440-1630.2011.00983.x

*Nilsson, L., Eklund, M., Nyberg, P., \& Thulesius, H. (2011). Driving to Learn in a powered wheelchair: The process of learning joystick use in people with profound cognitive disabilities. American Journal of Occupational Therapy, 65, 652-660. https://doi.org/10.5014/ajot.2011.001750

Patient Protection and Affordable Care Act, Pub. L. 111-148, 42 U.S.C. §§ 18001-18121 (2010).

*Precin, P., Otto, M., Popalzai, K., \& Samuel, M. (2012). The role for occupational therapists in community mobility training for people with autism spectrum disorders. Occupational Therapy in Mental Health, 28, 129-146. https://doi.org/10.1080/0164212X.2012.679533

Romli, M. H., Wan Yunus, F., \& Mackenzie, L. (2019). Overview of reviews of standardised occupation-based instruments for use in occupational therapy practice. Australian Occupational Therapy Journal, 66, 428-445. https://doi.org/10.1111/1440-1630.12572

*Samadi, S. A. (2011). The effect of handedness in vocational training among adults with intellectual disability. British Journal of Occupational Therapy, 74 , 581-586. https://doi.org/10.4276/030802211X13232584581498

*Sheppard, J. J., Malandraki, G. A., Pifer, P., Cuff, J., Troche, M., Hemsley, B., . . Hochman, R. (2017). Validation of the Choking Risk Assessment and Pneumonia Risk Assessment for adults with intellectual and developmental disability (IDD). Research in Developmental Disabilities, 69, 61-76. https://doi org/10.1016/j.ridd.2017.07.016

Simões, C., \& Santos, S. (2016). Comparing the quality of life of adults with and without intellectual disability. Journal of Intellectual Disability Research, 60, 378-388. https://doi.org/10.1111/jir.12256

*Sohlberg, M. M., Fickas, S., Lemoncello, R., \& Hung, P. F. (2009). Validation of the Activities of Community Transportation model for individuals with cognitive impairments. Disability and Rehabilitation, 31, 887-897. https://doi.org/10.1080/09638280802356260

*Stock, S. E., Davies, D. K., Wehmeyer, M. L., \& Lachapelle, Y. (2011). Emerging new practices in technology to support independent community access for people with intellectual and cognitive disabilities. NeuroRehabilitation, 28, 261-269. https://doi.org/10.3233/NRE-2011-0654

*Su, C. Y., Chen, C. C., Wuang, Y. P., Lin, Y. H., \& Wu, Y. Y. (2008). Neuropsychological predictors of everyday functioning in adults with intellectual disabilities. Journal of Intellectual Disability Research, 52, 18-28. https://doi.org/10.1111/j.1365-2788.2007.00969.X

*Su, C. Y., Lin, Y. H., Wu, Y. Y., \& Chen, C. C. (2008). The role of cognition and adaptive behavior in employment of people with mental retardation. Research in Developmental Disabilities, 29, 83-95. https://doi.org/10.1016/j.ridd.2006.12.001

*Taylor, J. L., Smith, L. E., \& Mailick, M. R. (2014). Engagement in vocational activities promotes behavioral development for adults with autism spectrum disorders. Journal of Autism and Developmental Disorders, 44, 1447-1460. https://doi.org/10.1007/s10803-013-2010-9

Thompson, J. R., Bryant, B. R., Campbell, E. M., Craig, E. P. M., Hughes, C. M., Rotholz, D. A., \& Wehmeyer, M. L. (2004). Supports Intensity Scale. American Association on Intellectual and Developmental Disabilities.

*Urwin, R., \& Ballinger, C. (2005). The effectiveness of sensory integration therapy to improve functional behaviour in adults with learning disabilities: Five single-case experimental designs. British Journal of Occupational Therapy, 68, 56-66. https://doi.org/10.1177/030802260506800202

Veritas Health Innovation. (2019). Covidence [Software]. Retrieved from https://www.covidence.org

*Waight, M. P., \& Oldreive, W. J. (2011). Evaluating the ability of and enabling a blind adult with learning disability to sign a tenancy agreement. British Journal of Learning Disabilities, 40, 55-61. https://doi.org/10.1111/j.1468-3156.2011.00683.x

Waldman-Levi, A., Golisz, K., Swierat, R. P., \& Toglia, J. (2019). Scoping review: Interventions that promote functional performance for adolescents and adults with intellectual and developmental disabilities. Australian Occupational Therapy Journal, 66, 458-468. https://doi.org/10.1111/1440-1630.12577

Wehmeyer, M. L. (1995). The ARC's Self-Determination Scale. ARC.

Wehmeyer, M. L., \& Abery, B. H. (2013). Self-determination and choice. Intellectual and Developmental Disabilities, 51, 399-411. https://doi.org/10.1352/ 1934-9556-51.5.399

*White, K., \& Mackenzie, L. (2015). Strategies used by older women with intellectual disability to create and maintain their social networks: An exploratory qualitative study. British Journal of Occupational Therapy, 78, 630-639. https://doi.org/10.1177/0308022615586419 
Wolman, J. M., Campeau, P. L., DuBois, P. A., Mithaug, D. E., \& Stolarski, V. S. (1994). AlR Self-Determination Scale and user guide. American Institutes for Research.

*Yalon-Chamovitz, S., \& Greenspan, S. (2005). Ability to identify, explain and solve problems in everyday tasks: Preliminary validation of a direct video measure of practical intelligence. Research in Developmental Disabilities, 26, 219-230. https://doi.org/10.1016/j.ridd.2004.08.002

Wanda J. Mahoney, PhD, OTR/L, is Associate Professor of Occupational Therapy and Medicine, Program in Occupational Therapy, Washington University School of Medicine, St. Louis, MO; wmahoney@wustl.edu

Meghan G. Blaskowitz, DrPH, MOTR/L, is Assistant Professor, Department of Occupational Therapy, Duquesne University, Pittsburgh, PA.

Khalilah R. Johnson, PhD, MS, OTR/L, is Assistant Professor, Division of Occupational Science and Occupational Therapy, University of North Carolina School of Medicine, Chapel Hill.

\section{Acknowledgments}

We thank David Nolfi, Head Librarian for Research Engagement, Health Sciences/STEM Initiatives, and Assessment, and Ted Bergfelt, Librarian at Duquesne University, for their methodological consultation and support in establishing and implementing search strategies for this scoping review. We also acknowledge the research assistance of occupational therapy students Rebecca Batchelor from the University of North Carolina at Chapel Hill, Lindsey Wethington from Washington University in St. Louis, and Emily Casile and Amy Castagnino from Duquesne University. 


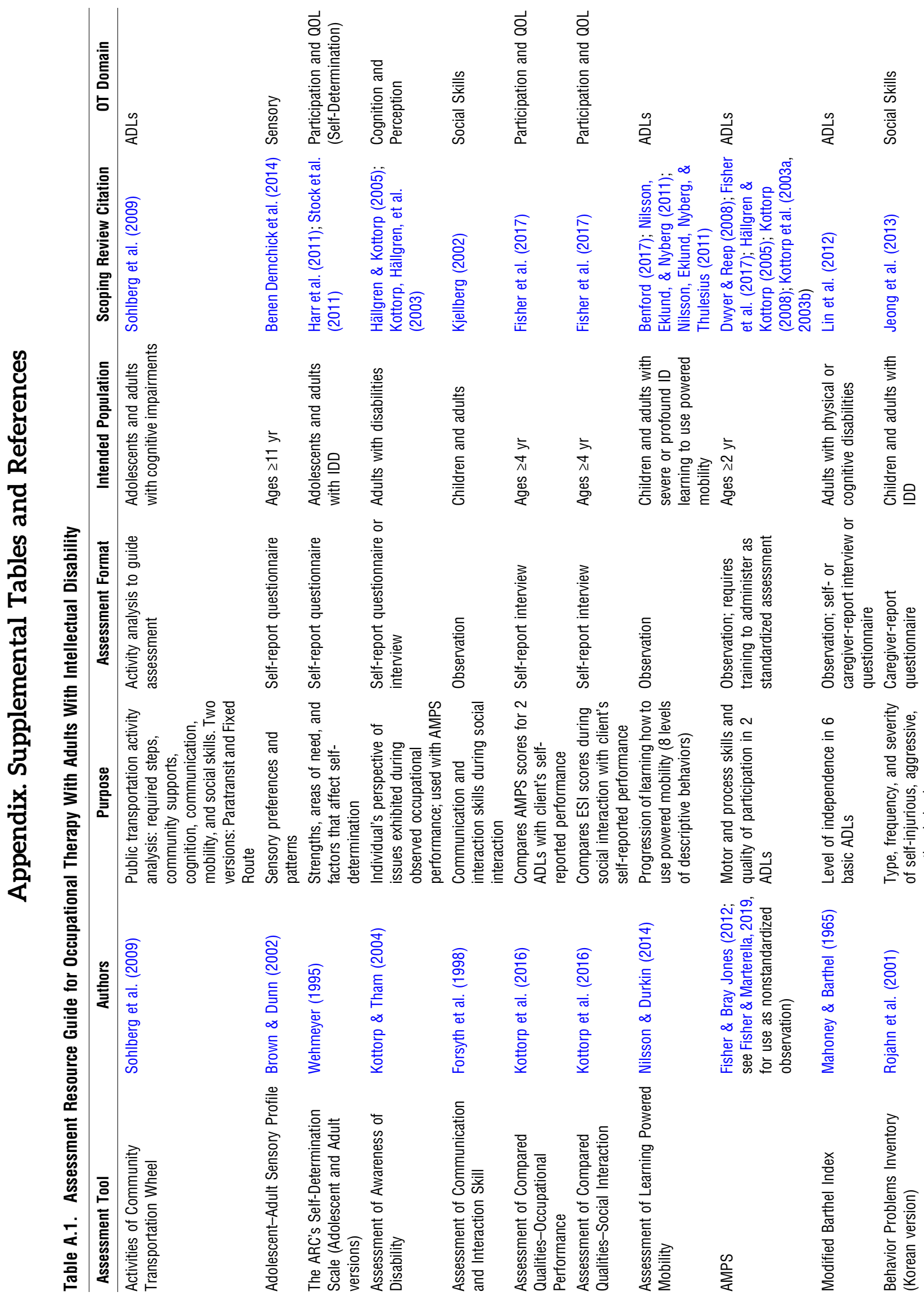




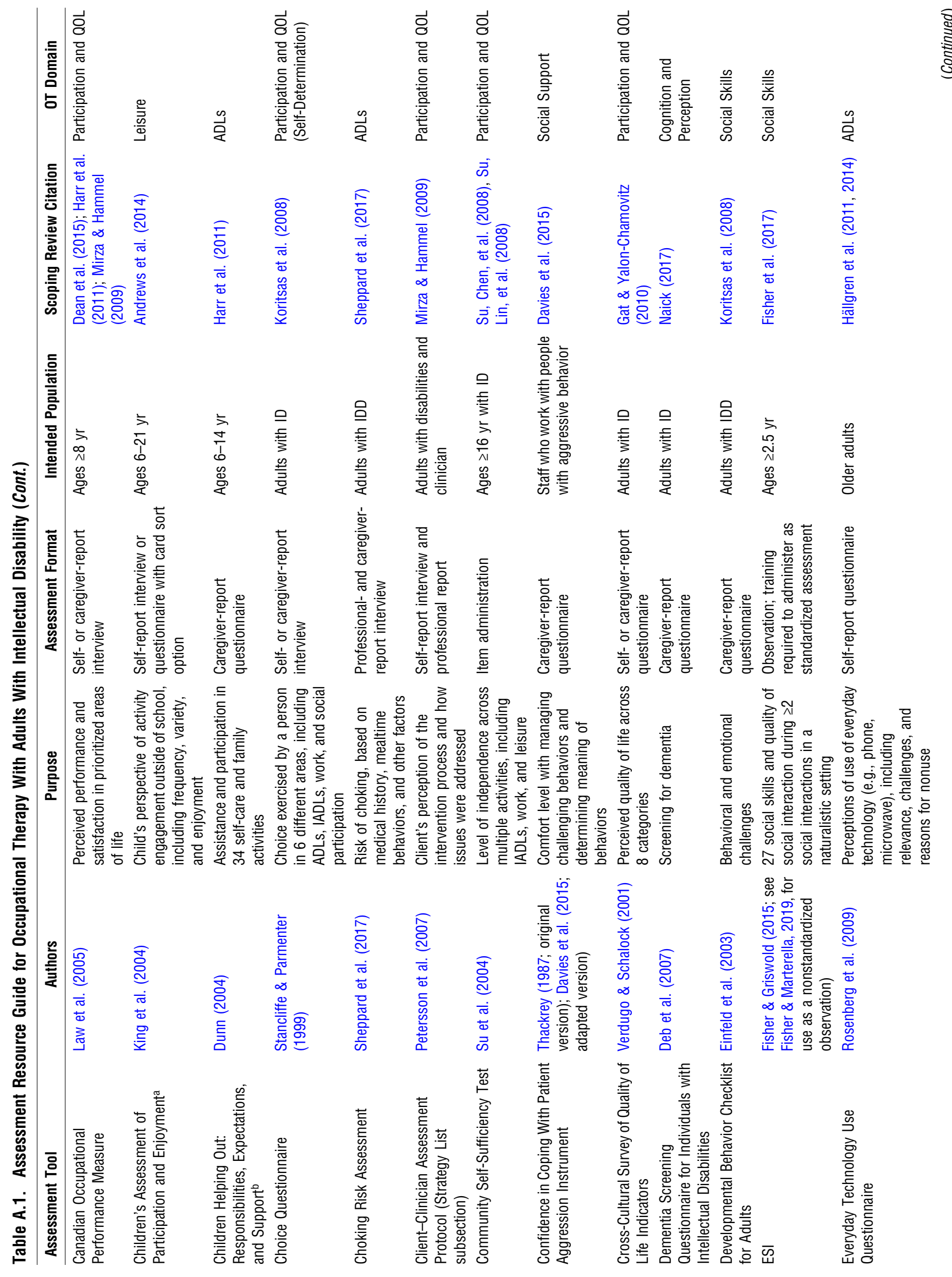




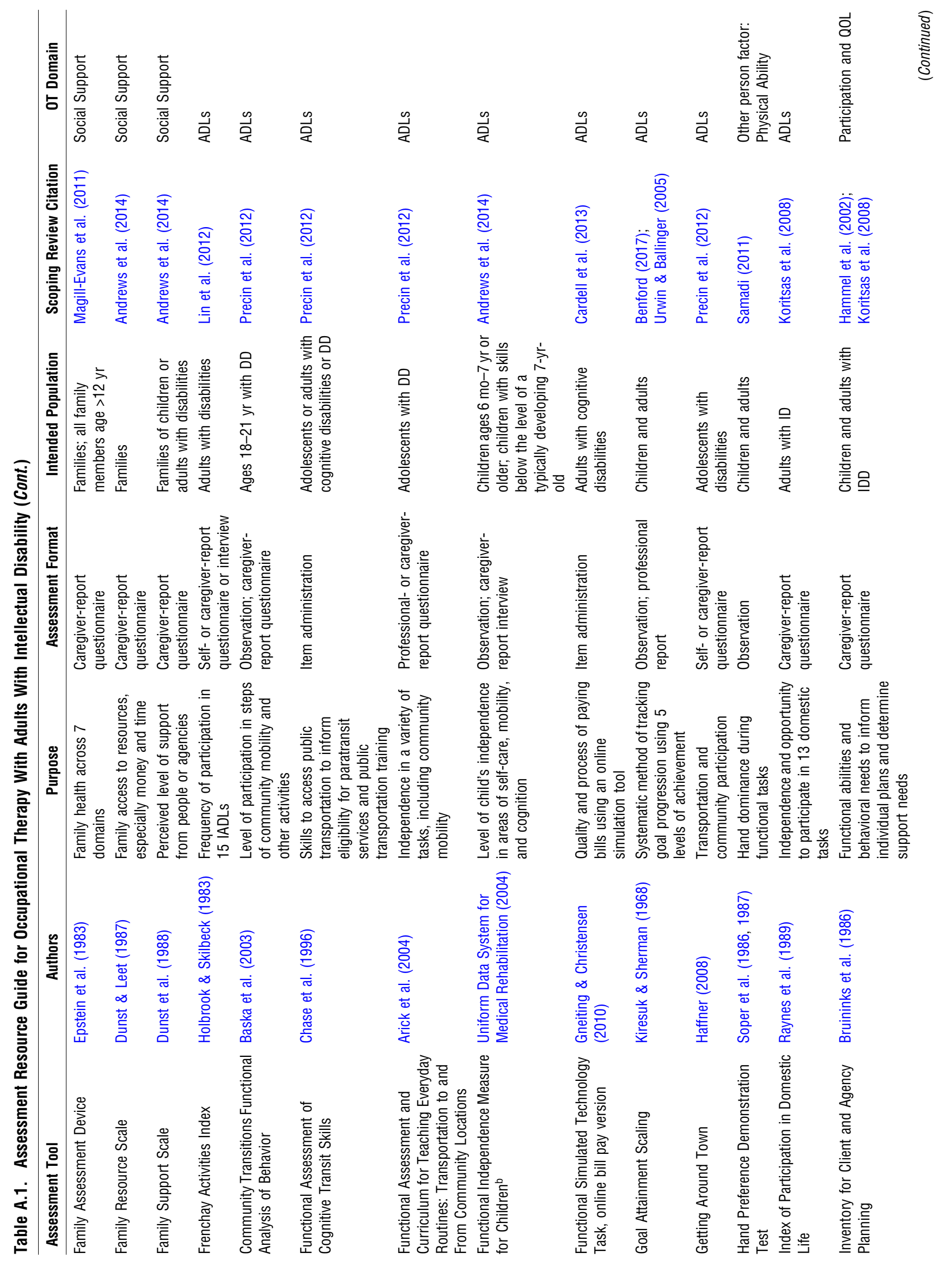




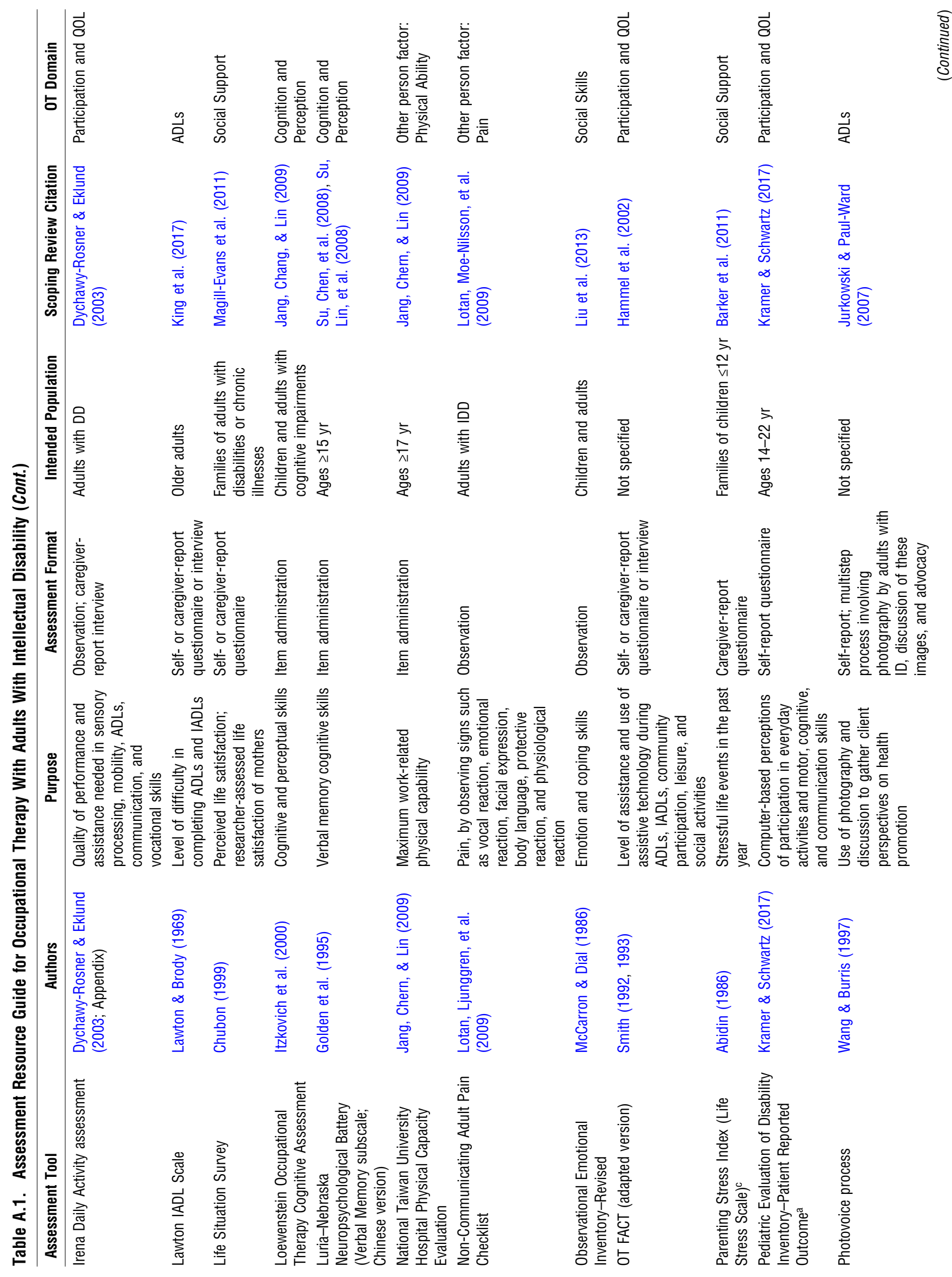




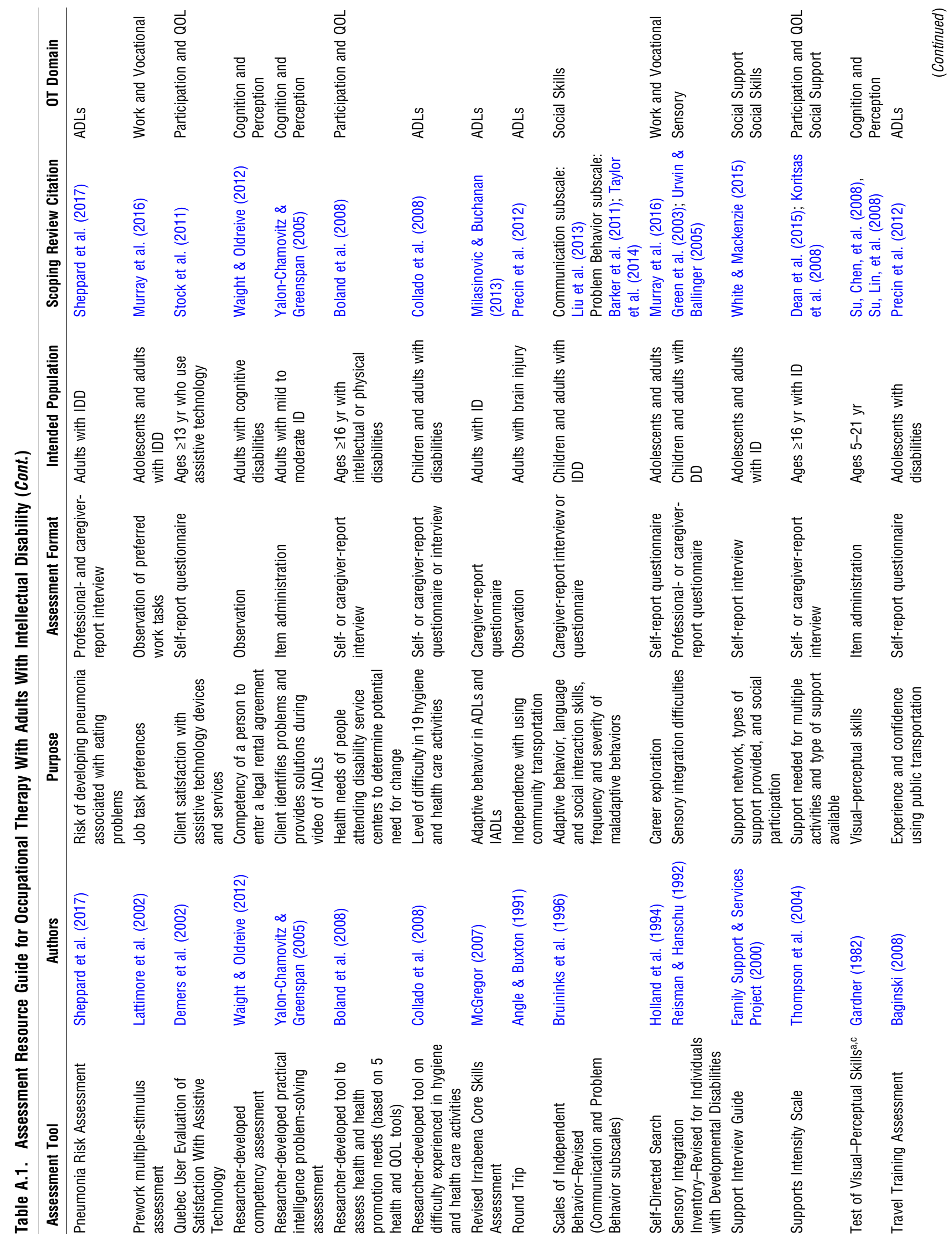




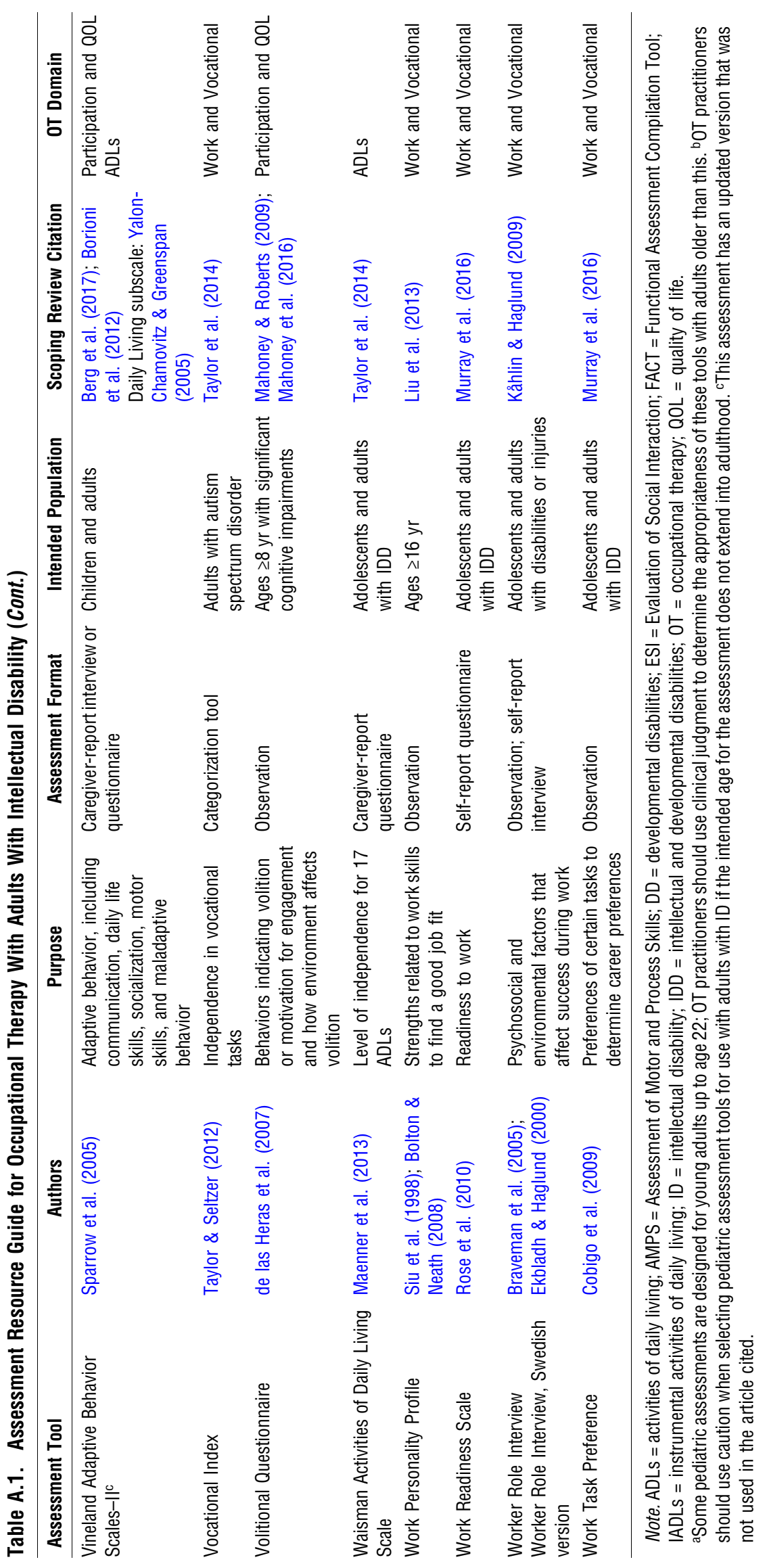




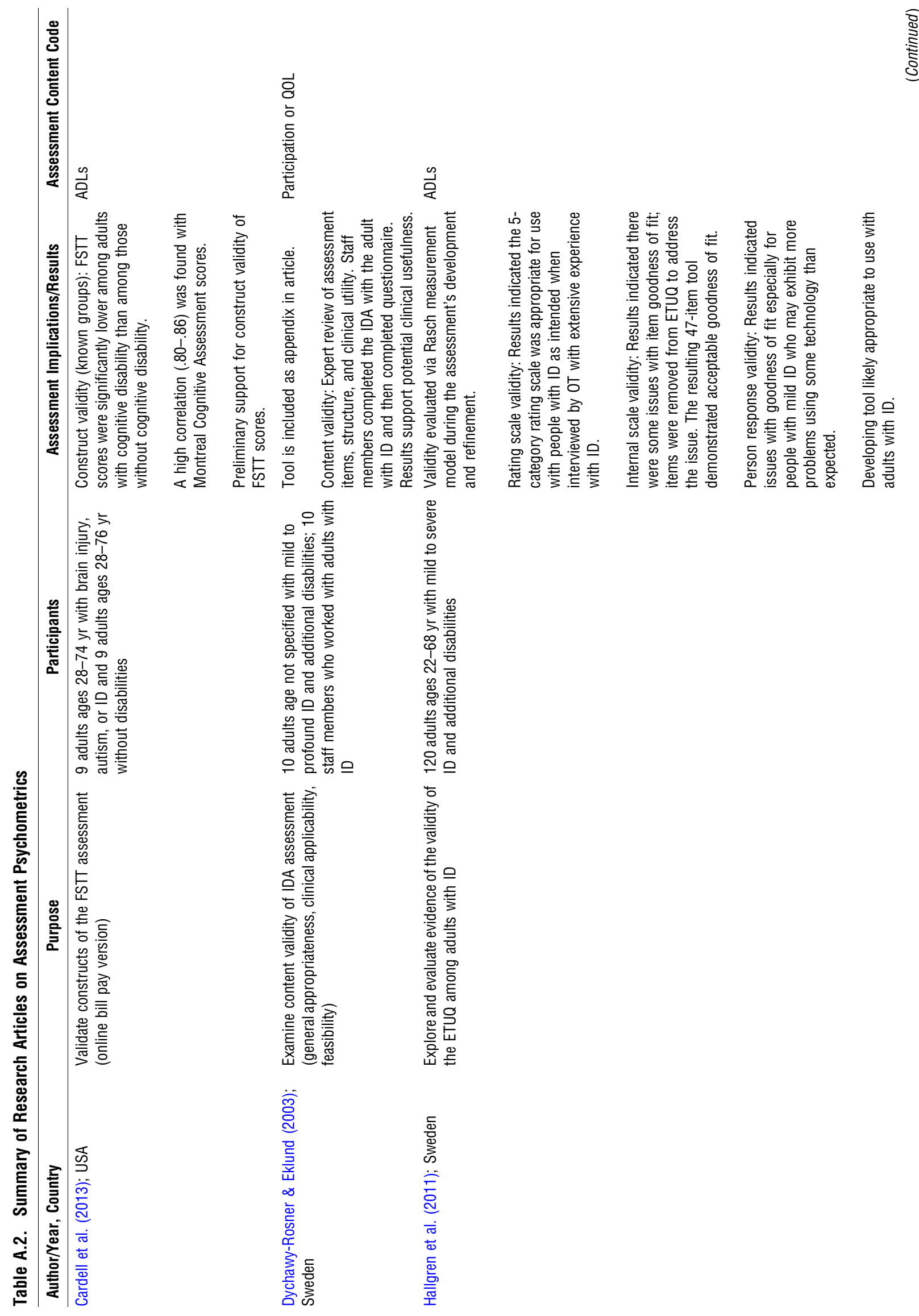




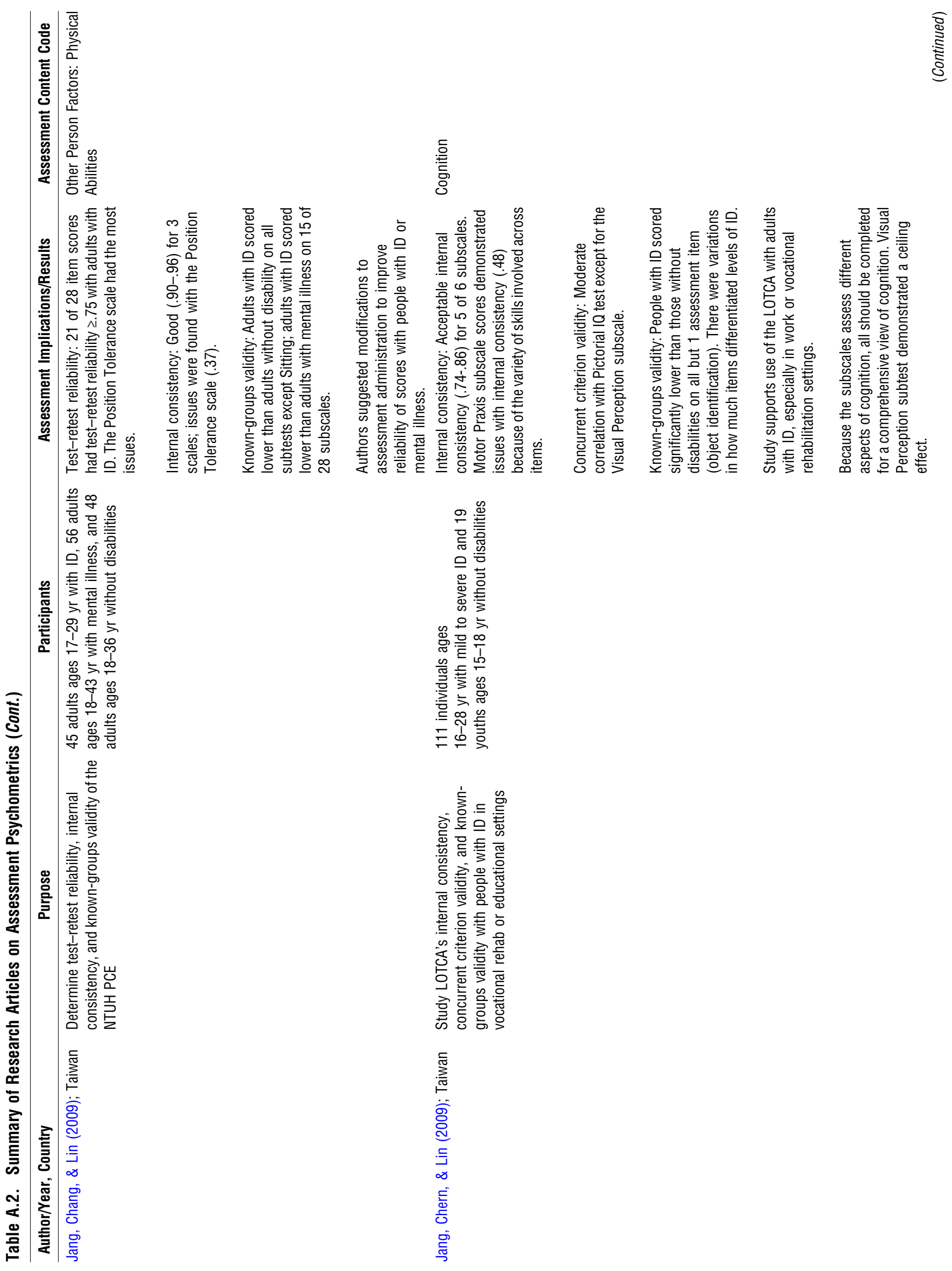




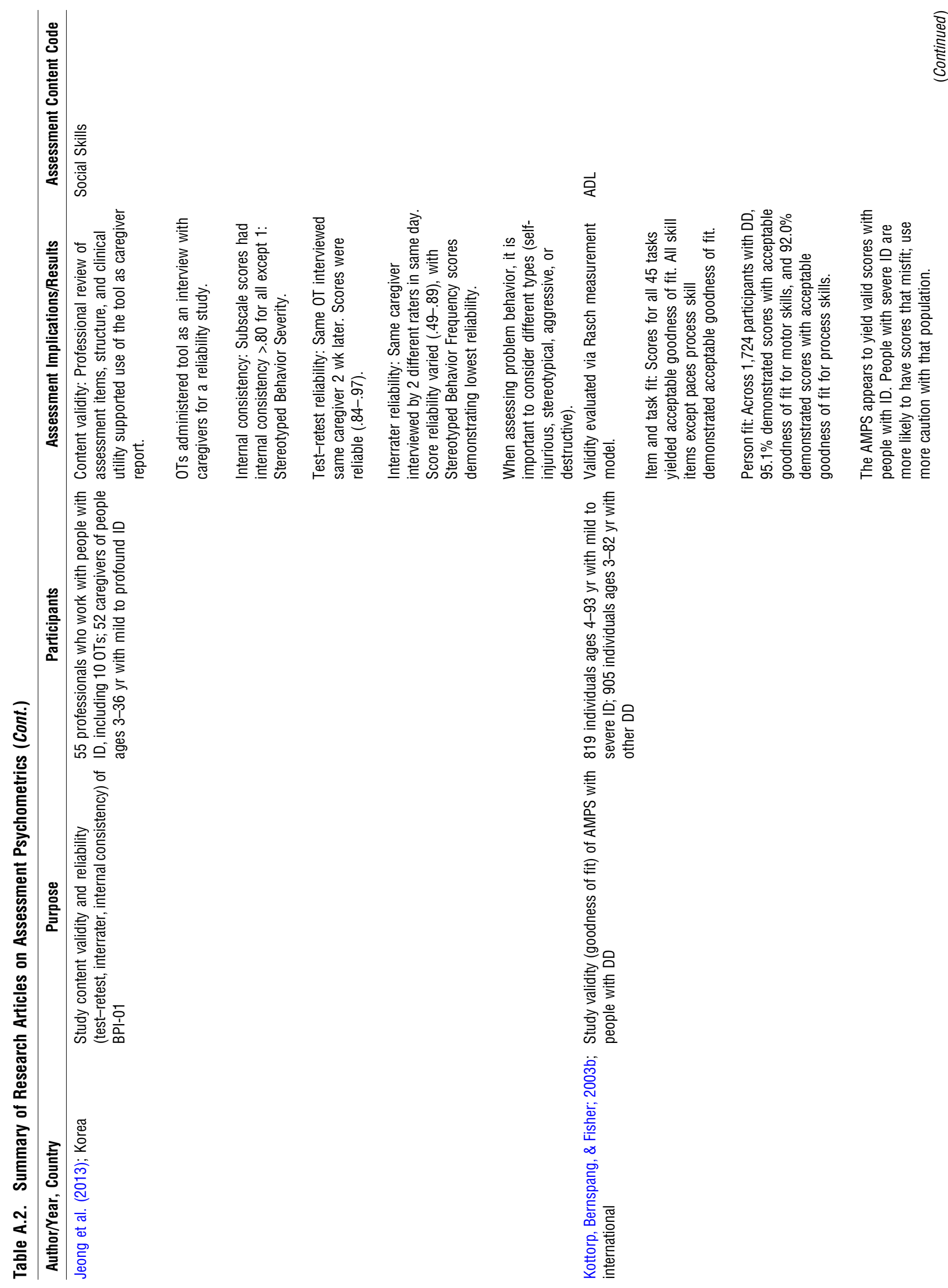



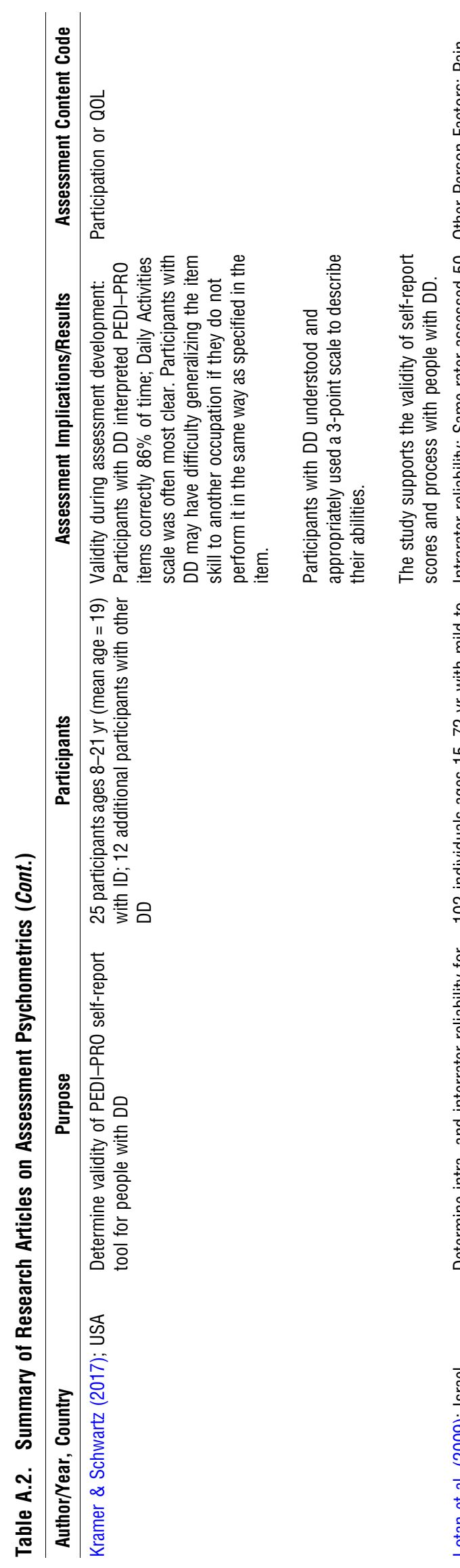

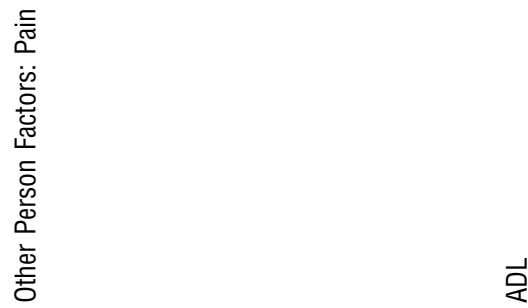

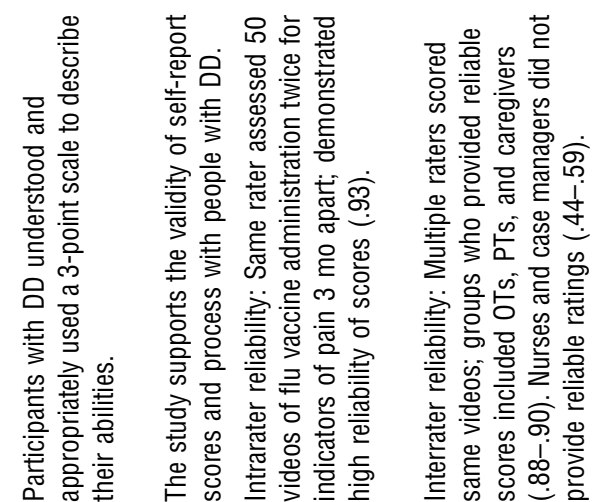

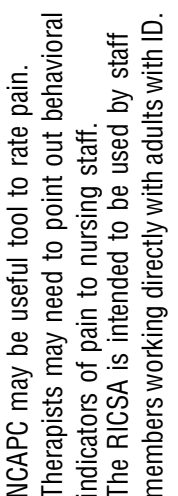

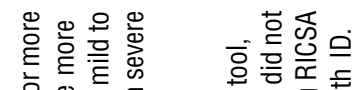

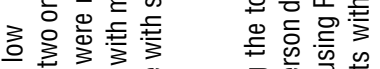

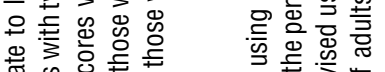

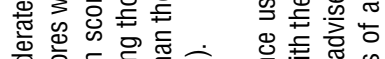

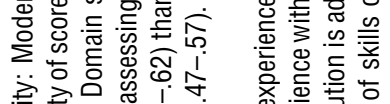
言 产

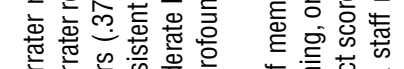

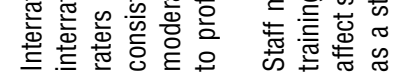

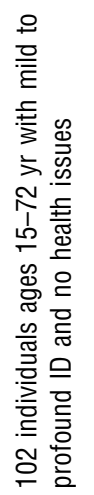

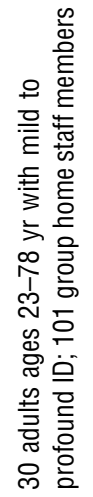

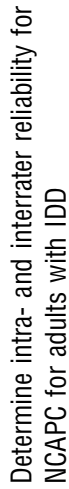

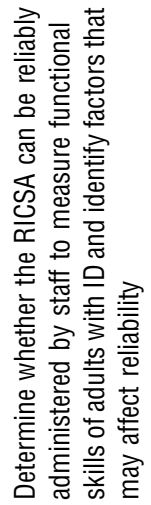

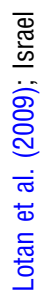

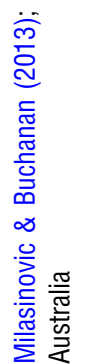




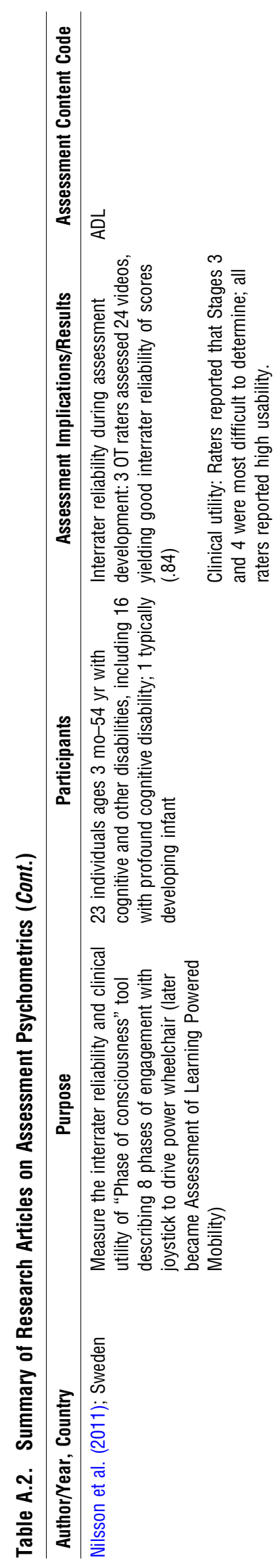

家

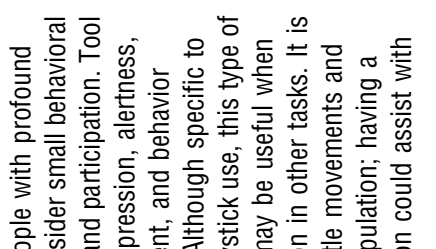

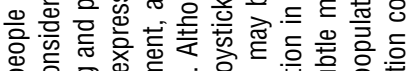

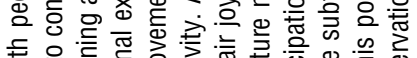

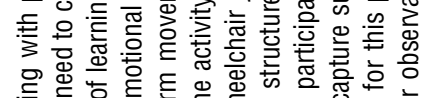

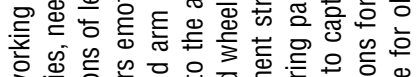

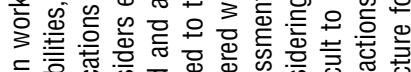

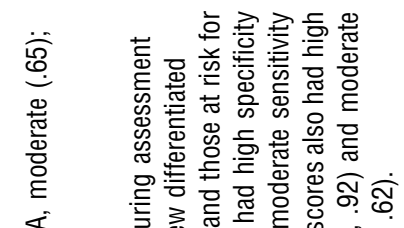

过

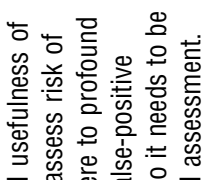

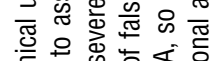

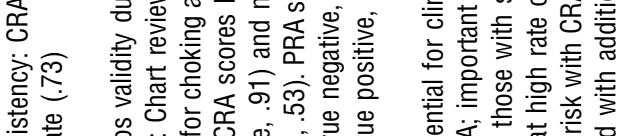

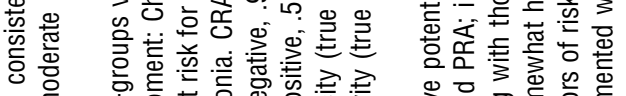

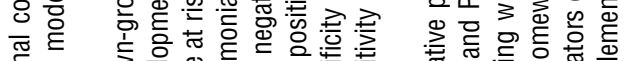

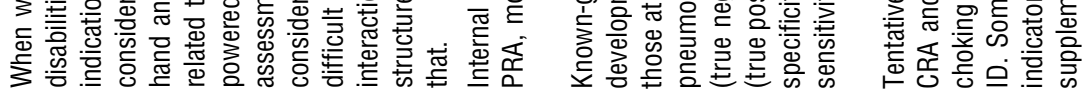

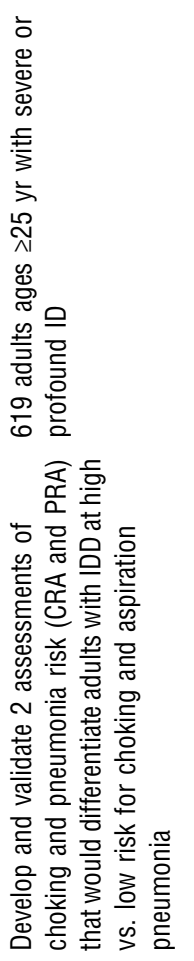

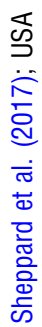




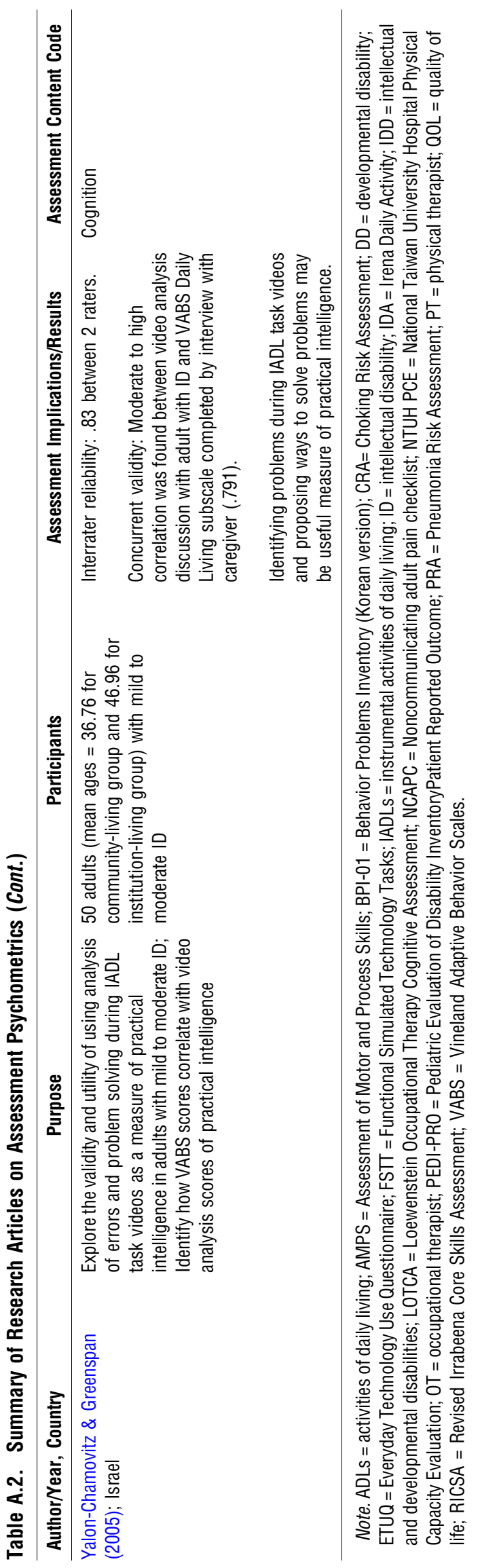




\section{Appendix References}

Abidin, R. A. (1986). Parenting Stress Index (2nd ed.). Pediatric Psychology Press.

Angle, D., \& Buxton, J. (1991). Community living skills workbook for the head injured adult. Aspen.

Arick, J., Nave, G., Hoffman, T., \& Krug, D. (2004). Functional assessment and curriculum for teaching everyday routines. PRO-ED.

Baginski, J. G. (2008). Travel training: An exploration of the importance of public transportation for suburban students with disabilities [Master's thesis]. Marietta College, Marietta, OH. https://etd.ohiolink.edu/apexprod/rws_olink/r/1501/10?clear=10\&p10_accession_num=marietta1209573613

Baska, L., Kaufman, A., Gaumer, A., Morningstar, M., Lattin, D., \& Peterson, T. (2003). The Community Transition Program: Experiences starting a community-based program for students ages 18-21. https://www.transitioncoalition.org/wp-content/uploads/2015/01/TC_Comm_Trans_Prog_Full_Doc. pdf

Braveman, B., Robson, M., Velozo, C., Kielhofner, G., Fisher, G., Forsyth, K., \& Kerschbaum, J. (2005). Worker Role Interview (WRI) (Version 10.0). Model of Human Occupation Clearinghouse.

Brown, C., \& Dunn, W. (2002). Adolescent Adult Sensory Profile. Therapy Skill Builders.

Bruininks, R., Hill, B., Weatherman, R., \& Woodcock, R. (1986). Inventory for Client and Agency Planning. DLM Teaching Resources.

Bruininks, R. H., Woodcock, R., Weatherman, R., \& Hill, B. (1996). Scales of Independent Behavior-Revised. Riverside.

Chase, S., Ratcliff, G., \& Hoesch, K. (1996). Functional Assessment of Cognitive Transit Skills. http://www.nadtc.org/wp-content/uploads/ 634712790936203900_Functional_Assessment_Co.pdf

Chubon, R. A. (1999). Manual for the Life Situation Survey. University of South Carolina.

Cobigo, V., Morin, D., \& Lachapelle, Y. (2009). A method to assess work task preferences. Education and Training in Developmental Disabilities, $44,561-572$. https://doi.org/10.1111/j.1741-1130.2010.00273.x

Demers, L., Weiss-Lambrou, R., \& Ska, B. (2002). The Quebec User Evaluation of Satisfaction with Assistive Technology (QUEST 2.0): An overview and recent progress. Technology and Disability, 14, 101-105. https://doi.org/10.3233/TAD-2002-14304

Dunn, L. (2004). Validation of the CHORES: A measure of school aged children's participation in household tasks. Scandinavian Journal of Occupational Therapy, 11, 179-190. https://doi.org/10.1080/11038120410003673

Dunst, C. J., Jenkins, V., \& Trivette, J. M. (1988). Enabling and empowering families: Principles and guidelines for practice. Brookline Books.

Dunst, C. J., \& Leet, H. E. (1987). Measuring the adequacy of resources in households with young children. Child: Care, Health and Development, 13, 111-125. https://doi.org/10.1111/j.1365-2214.1987.tb00528.x

Einfeld, S. L., Tonge, B. J., \& Mohr, C. (2003). Developmental Behaviour Checklist for Adults (DBC-A). Monash University.

Ekbladh, E., \& Haglund, L. (2000). Swedish Worker Role Interview (WRI-S) (Version 2). Linköpings Universitet.

Epstein, N. B., Baldwin, L. M., \& Bishop, D. S. (1983). The McMaster Family Assessment Device. Journal of Marital and Family Therapy, 9, 171-180. https:/l doi.org/10.1111/j.1752-0606.1983.tb01497.x

Family Support \& Services Project. (2000). The Support Interview Guide. http://sydney.edu.au/healthsciences/afdsrc/parents/resources/ SupportInterviewGuide.pdf

Fisher, A. G., \& Griswold, L. A. (2015). Evaluation of Social Interaction (3rd ed.). Three Star Press.

Forsyth, K., Salamy, M., Simon, S., \& Kielhofner, G. (1998). Assessment of Communication and Interaction Skills (ACIS). University of Illinois at Chicago.

Gardner, M. F. (1982). Test of Visual-Perceptual Skills. Psychological \& Educational Publications.

Gneiting, A., \& Christensen, B. (2010). Development of an occupation-based assessment of executive function, utilizing web-based technology. University of Utah.

Golden, C. J., Purisch, A. D., \& Hammeke, T. A. (1995). Luria-Nebraska Neuropsychological Battery Manual and Form. Western Psychological Services.

Haffner, J. (2008). Getting around town. In K. O. Synatschk, G. M. Clark, \& J. R. Patton (Eds.), Informal assessments for transition: Independent living and community participation. PRO-ED.

Holbrook, M., \& Skilbeck, C. E. (1983). An activities index for use with stroke patients. Age and Ageing, 12, 166-170. https://doi.org/10.1093/ageing/12.2.166 Holland, J. L., Powell, A. B., \& Fritzsche, B. A. (1994). The Self-Directed Search ${ }^{\text {TM }}$ (SDS ${ }^{T M}$ ). Psychological Assessment Resources.

Itzkovich, M., Elazar, B., Averbuch, S., \& Katz, N. (2000). Loewenstein Occupational Therapy Cognitive Assessment (LOTCA) Battery manual (2nd ed.). Maddak.

King, G., Law, M., King, S., Hurley, P., Hanna, S., Kertoy, M., ... Young, N. (2004). Children's Assessment of Participation and Enjoyment (CAPE) and Preferences for Activities of Children (PAC). Harcourt Assessment.

Kiresuk, T. J., \& Sherman, R. E. (1968). Goal Attainment Scaling: A general method for evaluating comprehensive community mental health programs. Community Mental Health Journal, 4, 443-453. https://doi.org/10.1007/BF01530764

Kottorp, A., Griswold, L. A., \& Fisher, A. G. (2016). Assessment of Compared Qualities: Occupational Performance and Social Interaction (3rd ed.). Three Star Press.

Kottorp, A., \& Tham, K. (2004). Assessment of Awareness of Disability. Karolinska Institutet.

Lattimore, L. P., Parsons, M. B., \& Reid, D. H. (2002). A prework assessment of task preferences among adults with autism beginning a supported job. Journal of Applied Behavior Analysis, 35, 85-88. https://doi.org/10.1901/jaba.2002.35-85

Lawton, M. P., \& Brody, E. M. (1969). Assessment of older people: Self-maintaining and instrumental activities of daily living. Gerontologist, 9, 179-186. https:// doi.org/10.1093/geront/9.3_Part_1.179 
Lotan, M., Ljunggren, E. A., Johnsen, T. B., Defrin, R., Pick, C. G., \& Strand, L. I. (2009). A modified version of the Non-Communicating Children Pain Checklist-Revised, adapted to adults with intellectual and developmental disabilities: Sensitivity to pain and internal consistency. Journal of Pain, 10 , 398-407. https://doi.org/10.1016/j.jpain.2008.09.006

Maenner, M. J., Smith, L. E., Hong, J., Makuch, R., Greenberg, J. S., \& Mailick, M. R. (2013). Evaluation of an activities of daily living scale for adolescents and adults with developmental disabilities. Disability and Health Journal, 6, 8-17. https://doi.org/10.1016/j.dhjo.2012.08.005

Mahoney, F. I., \& Barthel, D. W. (1965). Functional evaluation: The Barthel Index. Maryland State Medical Journal, 14, 61-65.

McCarron, L., \& Dial, J. (1986). McCarron-Dial Evaluation System: A systematic approach to vocational, educational and neuropsychological assessment. McCarron-Dial System.

Petersson, I., Fisher, A., Hemmingsson, H., \& Lija, M. (2007). The Client-Clinician Assessment Protocol (C-CAP): Evaluation of its psychometric properties for use with people aging with disabilities in need of home modifications. OTJR: Occupation, Participation and Health, 27, 140-148. https://doi.org/10.1177/ 153944920702700404

Raynes, N. V., Sumpton, R. C., \& Pettipher, C. (1989). Index of Participation in Domestic Life. University of Manchester.

Reisman, J. E., \& Hanschu, B. (1992). Sensory Integration Inventory-Revised for individuals with developmental disabilities. PDP Press.

Rojahn, J., Matson, J. L., Lott, D., Esbensen, A. J., \& Smalls, Y. (2001). The Behavior Problems Inventory: An instrument for the assessment of self-injury, stereotyped behavior, and aggression/destruction in individuals with developmental disabilities. Journal of Autism and Developmental Disorders, 31 , 577-588. https://doi.org/10.1023/A:1013299028321

Rose, J., Perks, J., Fidan, M., \& Hurst, M. (2010). Assessing motivation for work in people with developmental disabilities. Journal of Intellectual Disabilities, 14, 147-155. https://doi.org/10.1177/1744629510382067

Rosenberg, L., Nygård, L., \& Kottorp, A. (2009). Everyday Technology Use Questionnaire (ETUQ): Psychometric evaluation of a new assessment of competence in technology use. OTJR: Occupation, Participation and Health, 29, 52-62. 10.3928/15394492-20090301-05

Siu, A. M. H., Yau, M. K., \& Lam, P. C. W. (1998). The Chinese Work Personality Profile: Factor scales, reliability, and norms. Vocational Evaluation and Work Adjustment Bulletin, 31, 87-92.

Smith, R. O. (1992). OT FACT software and operating manual. American Occupational Therapy Association.

Smith, R. O. (1993). Computer-assisted functional assessment and documentation. American Journal of Occupational Therapy, 47, 988-992. https://doi.org/ 10.5014/ajot.47.11.988

Soper, H. V., Satz, P., Orsini, D. L., Henry, R. R., Zvi, J. C., \& Schulman, M. (1986). Handedness patterns in autism suggest subtypes. Journal of Autism and Developmental Disorders, 16, 155-167. https://doi.org/10.1007/BF01531727

Soper, H. V., Satz, P., Orsini, D. L., Van Gorp, W. G., \& Green, M. F. (1987). Handedness distribution in a residential population with severe or profound mental retardation. American Journal of Mental Deficiency, 92, 94-102.

Sparrow, S. S., Cicchetti, D. V., \& Balla, D. A. (2005). The Vineland Adaptive Behavior Scales (2nd ed.). Pearson.

Stancliffe, R. J., \& Parmenter, T. R. (1999). The Choice Questionnaire: A scale to assess choices exercised by adults with intellectual disability. Journal of Intellectual and Developmental Disability, 24, 107-132. https://doi.org/10.1080/13668259900033911

Su, C. Y., Chen-Sea, M. J., Lin, C. L., Lin, Y. H., Wu, Y. Y., \& Chang, J. J. (2004). Development of a computerized community self-sufficiency test. Journal of Taiwan Occupational Therapy Association, 22, 15-34.

Taylor, J. L., \& Seltzer, M. M. (2012). Developing a vocational index for adults with autism spectrum disorders. Journal of Autism and Developmental Disorders, 42, 2669-2679. https://doi.org/10.1007/s10803-012-1524-x

Thackrey, M. (1987). Clinician confidence in coping with patient aggression: Assessment and enhancement. Professional Psychology: Research and Practice, 18, 57-60. https://doi.org/10.1037/0735-7028.18.1.57

Uniform Data System for Medical Rehabilitation. (2004). WeeFIM I/ system [Computer software]. University at Buffalo, State University of New York.

Verdugo, M. A., \& Schalock, R. (2001). Cross-cultural survey of quality of life indicators. Institute on Community Inclusion.

Wang, C., \& Burris, M. A. (1997). Photovoice: Concept, methodology, and use for participatory needs assessment. Health Education and Behavior, 24, 369-387. https://doi.org/10.1177/109019819702400309 